\title{
Study on oscillation modes of weld pool in stationary GTA welding using structure laser method
}

\section{Xingpei Wu}

Lanzhou University of Technology

Jiankang Huang ( $\sim$ sr2810@163.com )

Lanzhou University of Technology https://orcid.org/0000-0002-1257-8622

Jing He

Southern University of Science and Technology

Shien Liu

Lanzhou University of Technology

\section{Guangyin Liu}

Lanzhou Branch National Science Library Chinese Academy of Sciences

\section{Ding Fan}

Lanzhou University of Technology

\section{Original Article}

Keywords: Weld pool surface, GTA Welding, Bessel function, vibration mode, geometric optics

Posted Date: May 5th, 2020

DOI: https://doi.org/10.21203/rs.3.rs-26293/v1

License: (c) (i) This work is licensed under a Creative Commons Attribution 4.0 International License. Read Full License

Version of Record: A version of this preprint was published at Chinese Journal of Mechanical Engineering on September 19th, 2021. See the published version at https://doi.org/10.1186/s10033-021-00609-9. 


\title{
Study on oscillation modes of weld pool in
}

\section{stationary GTA welding using structure laser method}

\author{
WU Xingpei ${ }^{1}$, HUANG Jiankang ${ }^{1, *}$, HE Jing ${ }^{2, *}$, LIU Shien ${ }^{1}$, LIU Guangyin ${ }^{3}$, FAN Ding ${ }^{3, *}$ \\ 1. Materials Science and Engineering College, Lanzhou University of Technology, Lanzhou 730050, China \\ 2. Department of Mechanical Energy Engineering, Southern University of Science and Technology, Shenzhen 518055, \\ China \\ 3. State Key Laboratory of Advanced Processing and Recycling of Non-Ferrous Metals, Lanzhou University of \\ Technology, Lanzhou 730050, China
}

\begin{abstract}
To study the oscillation mode of GTA weld pool, the oscillation mode of weld pool was analyzed based on Bessel equation, and the laser dot matrix images of $(0,1),(1,1),(2,1),(0,2)$ oscillation modes at different times are obtained by structured laser optical measurement simulation. The oscillation mode of stationary GTA weld pool was analyzed based on the laser dot matrix images obtained by structure laser experiment. The result shows the simulated laser dot matrix images matches up to the experiment result. The oscillation mode of the weld pool can be recognized based on laser dot matrix image. This study can not only provide conditions for judging the penetrating state of weld pool, but also help to further understand the oscillation mode of the weld pool and develop more effective observation methods and measurement tools, so as to effectively control and improve the welding quality.
\end{abstract}

Keywords: Weld pool surface; GTA Welding; Bessel function; vibration mode; geometric optics;

\section{Introduction}

Gas tungsten $\operatorname{arc}(\mathrm{GTA})$ welding is a form of fusion welding where an electric arc is applied to the surfaces of parts to melt and join parts ${ }^{[1]}$. The weld pool contains a lot of information about the change of physical state during the process of welding and plays a basic role in determining the result of welding. The size of weld pool directly affects the appearance and internal quality of the weld. The stability of the size of weld pool during the welding process is very important for the quality of the weld. Many recent studies focus on it. Rebuilding the three-dimensional shape of the pool surface can not only provide experimental verification means for numerical simulation of welding thermal process, but also lay a solid foundation for intelligent control of welding process, which has important theoretical significance and engineering application value. However, in the process of welding, it is very difficult to observe the three-dimensional morphology of GTA weld pool surface because of the adverse factors such as fast change of pool surface, splashing and arc intensity. At the same time, electromagnetic interference, high-temperature plasma

\footnotetext{
* Corresponding author:
}

HUANG Jiankang, Email: sr2810@163.con;

HE Jing, Email: hejing0229@gmail.com.

FAN Ding, Email: fand@lut.cn;

This work was funded by National Natural Science Foundation of China (No.51205197) and high-temperature pool exist in welding. It is not suitable to obtain three-dimensional information by mechanical and electromagnetic methods in the process of welding. The need for real-time measurement of weld pool height information lead to infrared sensing and $\mathrm{X}$-ray methods cannot be used.

For the sensor measurement of GTA welding pool surface, domestic and foreign scholars have studied it by many methods. In the actual welding process, optical measurement technology is mainly used, such as structured light three-dimensional visual measurement method ${ }^{[2]}$, SFS (shape from shading) ${ }^{[3]}$ and binocular stereo vision method ${ }^{[4]}$.In numerical simulation, the finite element analysis method and other numerical simulation software ${ }^{[5-7]}$ are mainly used.

Among them, structured laser optical measurement mainly uses the combination of optical principle, visual measurement technology and image processing method to obtain three-dimensional data of objects. Because of its non-contact, high precision, high resolution and portability, it has become the focus of research at home and abroad.

In order to analyze and measure surface distortion of weld pool, Zhening Cao et al. ${ }^{[8]}$ deduced the calculation formula of surface distortion of GTA weld pool by using hydrodynamic theory; PALANI P. K. et al. [9] studied the influence of pulse parameters on arc stability, welding quality, weld morphology and geometry parameters of welds. Yukang Liu et al. [10] used a new machine vision system to measure the 
three-dimensional weld pool interface of GTAW in real time, and characterized the width, length and concavity of the weld pool; H. K. Narang et al. ${ }^{[11]}$ established a fuzzy logic model to predict the shape and profile characteristics of HAZ macrostructure area and GTA pool geometry; Jingshan He et al. ${ }^{[12]}$ and Fenggui $\mathrm{Lu}^{[13]}$ used the finite element analysis software to analyze the three-dimensional surface of welding pool; Shinobu Satonaka et al. ${ }^{[14]}$ measured the free surface of the weld pool by optical method and image analysis method. G Saeed et al. ${ }^{[15]}$ proposed a method to extract surface information such as pool depth from captured images by using calibrated charge coupled device (CCD) sensors and structured light. Hiroshi Maruo et al. ${ }^{[16]}$ studied the relationship between the vibration frequency and the oscillation mode of the circular weld pool. W Wang. et al. [17] studied the characteristic information of GMAW-P weld pool surface fluctuation with the methods of structured laser reflection and electrical signal sensing. They found that the fluctuation amplitude of the weld pool surface was determined by the size of the weld pool. With the increase of the penetration degree, the fluctuation amplitude of the weld pool surface decreased. Y. Hirata et al. ${ }^{[18]}$ developed a three-dimensional weld pool flow model with a free surface, used the VOF (volume of fluid) method to track the change of the surface shape of the weld pool with time, and the CSF (continuous surface force) method to calculate the tension produced by the surface deformation of the weld pool.

There are also a lot of research work in the realization of automatic welding. Shanben Chen et al. ${ }^{[19]}$ introduced identification models and intelligent models into the weld pool dynamics during pulsed GTAW; Yukang Liu et al. ${ }^{[20]}$ proposed a three-dimensional surface control system of weld pool based on the intelligent response model of human welders, which laid the foundation for quickly transforming the intelligence of skilled welders into robot welding system; Wei Lu et al. ${ }^{[21]}$ established a framework for developing a novel robust sensing and control system for the depth of the weld pool surface which can work under different manufacturing conditions; Choong D. YOO et al. ${ }^{[22]}$ conducts an experimental study on the oscillation of a weld pool suitable for the geometry measurement of the weld pool through arc voltage and light emission during GTA welding. And find out the characteristics of pool oscillation signals in full and transition penetration pools; G Saeed et al. ${ }^{[23]}$ and Xuewu Wang ${ }^{[24]}$ proposed a new method of three-dimensional weld pool calculation based on laser specular reflection and developed it into three-dimensional measurement technology to achieve accurate measurement and Simulation of different weld pool surface morphology; Yukang Liu et al. [25] constructed a novel machine vision system using structured laser to measure the geometric dimensions of the surface of three-dimensional weld pool in real time, and presented a predictive control algorithm for automatic welding. Hongsheng Song et al. ${ }^{[26]}$ studied the image processing algorithm after the dot matrix laser pattern reflected from the weld pool surface, and obtained the data needed to reconstruct the pool surface based on the reflection law.

COMSOL Multiphysics has high efficiency of computer performance and unique multi field full coupling analysis capability, so it can ensure the high accuracy of numerical simulation ${ }^{[27]}$. In this paper, the oscillation modes of weld pool were analyzed based on Bessel equation. The laser dot matrix images of $(0,1),(1$, $1),(2,1),(0,2)$ oscillation modes at different times are obtained by structured laser optical measurement simulation. The oscillation mode of stationary GTA weld pool was analyzed based on laser dot matrix images and simulation results. This is helpful for further develop the basic research work of welding technology, so as to effectively control and improve the quality of welding.

\section{Weld pool surface and circular membrane vibration}

\subsection{Observation experiment of weld pool surface}

The geometric relationship of each component of the measurement system is shown in the Fig. 1a. The observation system of weld pool surface in stationary GTA welding is mainly composed of structure laser reflection imaging system and laser vision acquisition system. The laser is placed in the $\mathrm{x}-\mathrm{z}$ plane, which is $45^{\circ}$ aligned with the workpiece horizontally and placed $17.1 \mathrm{~mm}$ away from the torch. The imaging plane is $45^{\circ}$ aligned with the workpiece. The distance between the center point and the workpiece is $11.32 \mathrm{~mm}$, and the distance between the camera and the workpiece is $48.08 \mathrm{~mm}$. The laser has a rated voltage (DC) of $3 \mathrm{~V}$, a power of $200 \mathrm{~mW}$ and a wavelength of $650 \mathrm{~nm}$. The laser vision acquisition system is mainly composed of a CCD industrial camera behind the imaging plane, with a spectral response of 340-1030 $\mathrm{nm}$ and a signal-to-noise ratio of $38 \mathrm{~dB}$. In Fig. 1b, the geometric relationship of the system is shown more specifically, which is helpful to simplify the correlation transformation and better describe the behavior of the weld pool. 

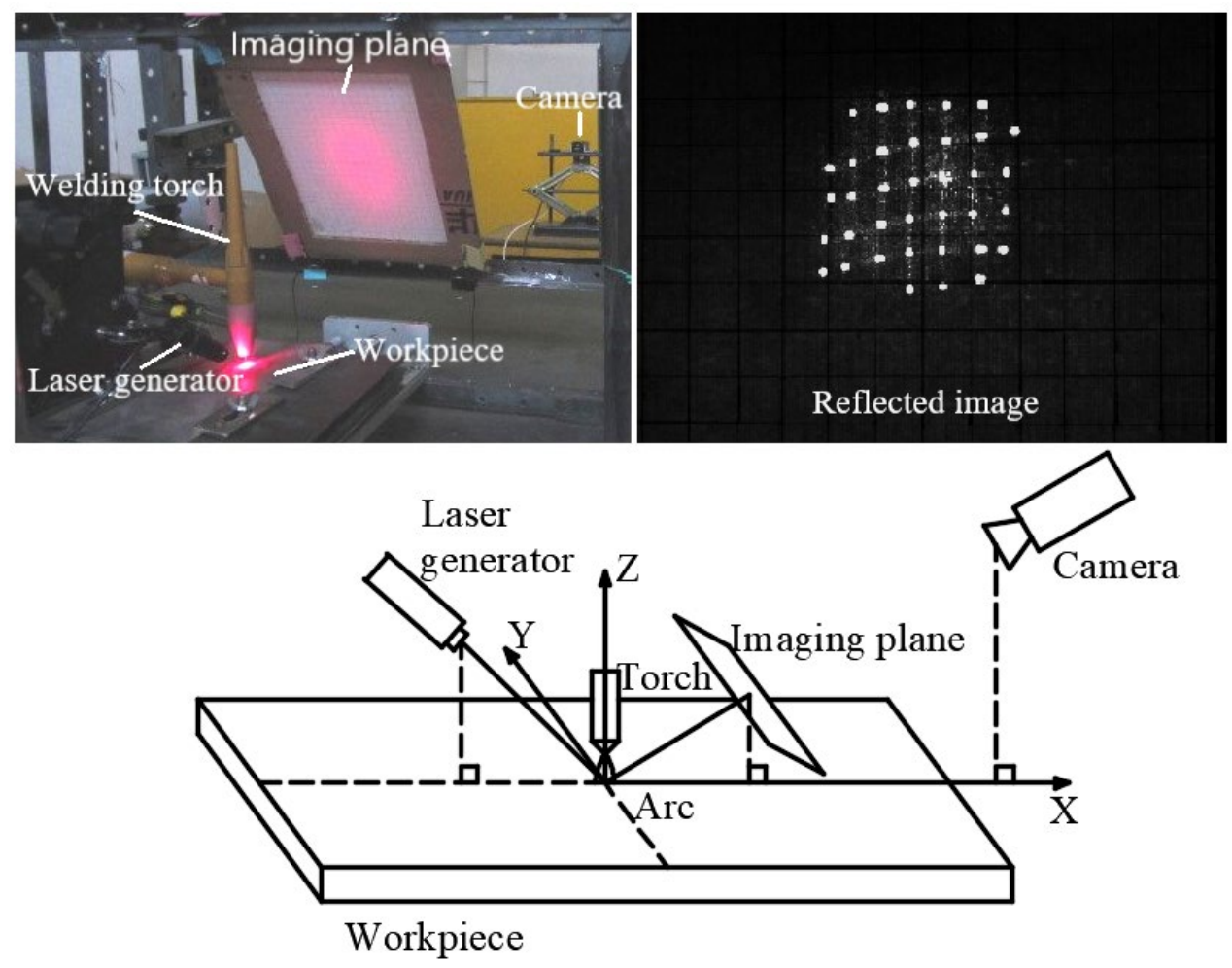

(a)

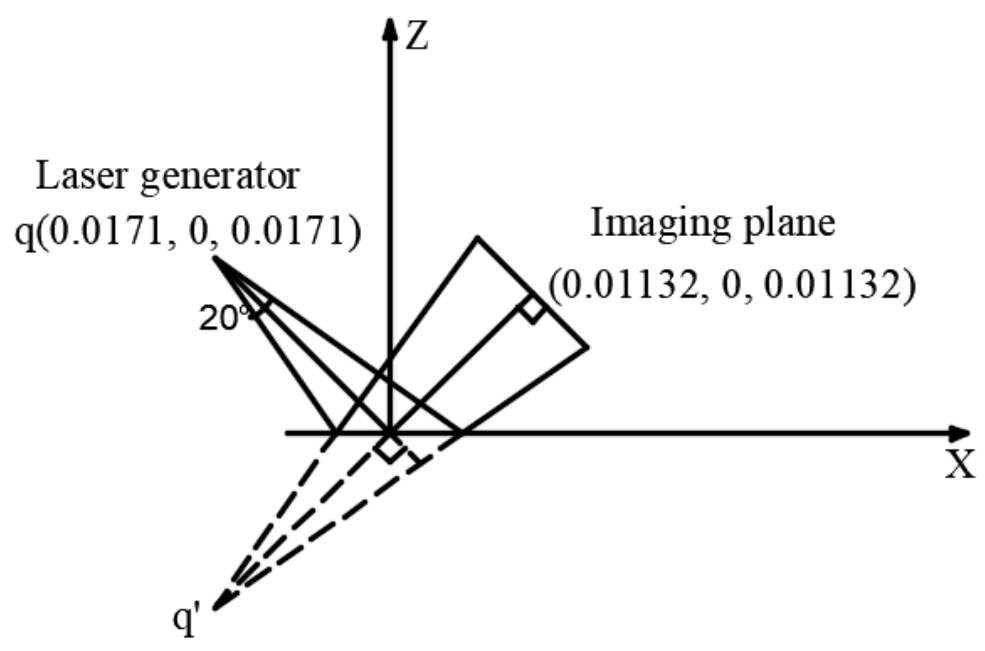

(b)

Fig. 1 Schematic diagram of the test system

The stationary GTA welding was conducted to observe the weld pool surface based on the test system. The 304 stainless steel plate with the size of $125 \mathrm{~mm} \times 50$ $\mathrm{mm} \times 3 \mathrm{~mm}$ was used in the experiment. The welding current was $70 \mathrm{~A}$, argon flow was $10 \mathrm{~L} / \mathrm{min}$. Under the condition of welding process parameters, the oscillation of weld pool was captured at $1000 \mathrm{f} / \mathrm{s}$ by the high-speed camera during welding. After processing the video image frame by frame, a typical image of the laser grid was selected, as shown in Fig. 2. It can be seen that the number of adjacent laser points in Fig. 2a-c increases gradually, the distance between laser points increases gradually, the shape of the midpoint array in Fig. 2d-g does not change much, the midpoint array in Fig. $2 \mathrm{~h}-\mathrm{k}$ begins to converge to the middle, and the midpoint array in Fig. 21 almost gathers together. 


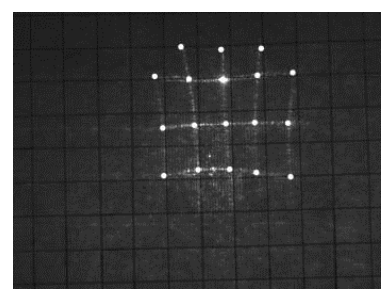

(a)

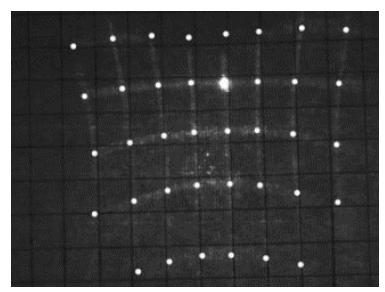

(e)

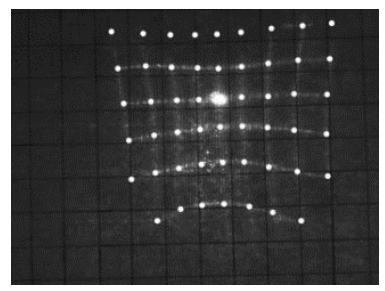

(i)

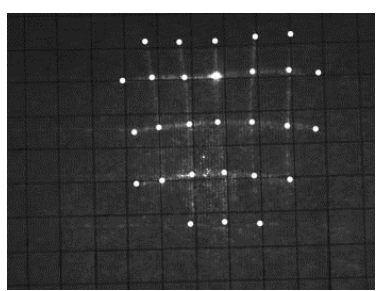

(b)

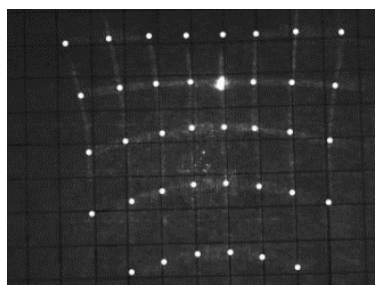

(f)

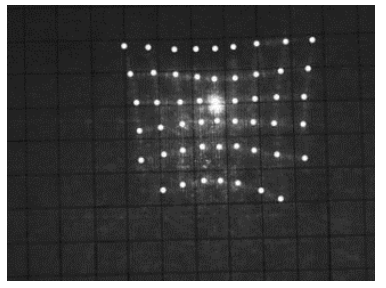

(j)

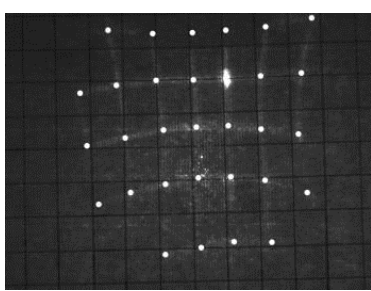

(c)

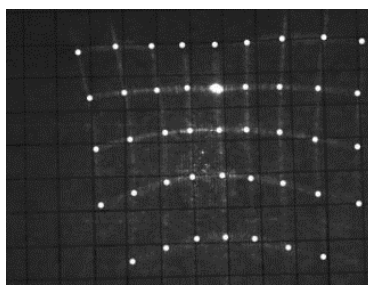

(g)

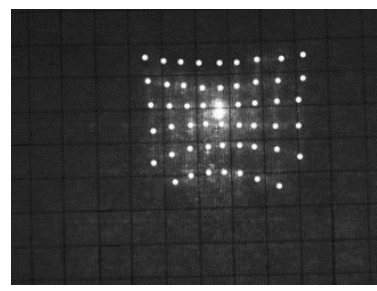

(k)

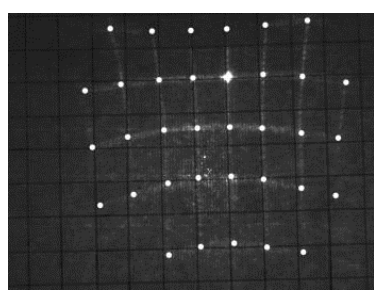

(d)

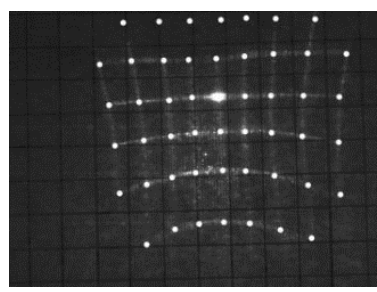

(h)

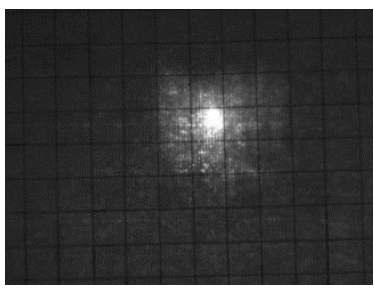

(1)

Fig. 2 Laser dot matrix images at 70A in GTA welding

When the pool is oscillated by excitation, the oscillation amplitude of weld pool surface is small, but the laser reflection angle caused by the pool oscillation changes greatly. The lattice on the imaging plane has a good optical amplification effect on the weld pool oscillation. Because the arc radiation intensity decays off squarely with the increase of distance, and the laser intensity does not decrease with the change of distance. An image screen is placed at the appropriate location from the torch to accept the amplified reflected laser stripe signal. Under the joint action of surface tension, arc pressure, electromagnetic force and buoyancy, concave and convex phenomenon of weld pool surface will appear in the pool.

\subsection{Circular membrane vibration and Bessel}

\section{function}

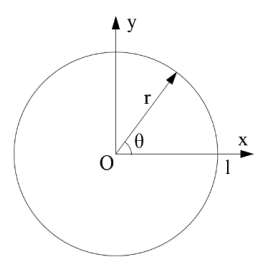

Fig. 3 Transverse vibration of circular membrane
If the weld pool surface is regarded as a two-dimensional membrane with a radius of $l$ and a fixed periphery, as shown in Fig. 3, it will fluctuate and vibrate with the action of arc force and surface tension. At the same time, it will be affected by the boundary conditions, these take the form

$$
\left\{\begin{array}{l}
u(l, \theta, t)=0 \\
u(r, 0, t)=u(r, 2 \pi, t) .
\end{array}\right.
$$

This kind of resonance is similar to the form of standing wave, that is, the eigenfrequency of resonance can only be found on some determined value. Since this is a two-dimensional problem, it is solved in polar coordinate system. The two-dimensional wave equation can be expressed as partial differential equation in the form of polar coordinates:

$$
\begin{gathered}
\frac{1}{V^{2}} \frac{\partial^{2} u}{\partial t^{2}}=\frac{1}{r} \frac{\partial}{\partial r}\left(r \frac{\partial u}{\partial r}\right)+\frac{1}{r^{2}} \frac{\partial^{2} u}{\partial \theta^{2}}+f \\
c=V^{2}=\frac{T}{\rho}
\end{gathered}
$$

where $c$ is the diffusion coefficient and $V$ is the propagation velocity of wave, and depends on membrane surface tension and density, $f$ is the source term, 
representing supply or consumption of dependent variables throughout the entire physical field. When $f=0$, the circular membrane is vibrated by a free surface.

Supposing that $u(r, \theta, t)=z(r, \theta) T(t)$ and $Z(r, \theta)=Z(r) \phi(\theta)$, using the method of separating variables. Therefore, the partial differential equation is transformed into following ordinary differential equations

$$
\begin{gathered}
\frac{d^{2} \phi}{d \theta^{2}}+n^{2} \phi=0 \\
\frac{d^{2} z_{n}}{d r^{2}}+\frac{1}{r} \frac{d z_{n}}{d r}+\left(k^{2}-\frac{n^{2}}{r^{2}}\right) z_{n}=0
\end{gathered}
$$

The solution of equation (4) can be written in the form

$$
\phi(\theta)=c_{1} \sin (n \theta+\varphi)
$$

Equation (5) is Bessel's equation, where $k=\frac{\omega}{V}$, its general solution is

$$
Z_{0}(r)=c_{2} J_{n}(k r)+c_{3} N_{n}(k r)
$$

where $J_{n}(k r)$ is Bessel functions of the first kind, $N_{n}(k r)$ is Bessel functions of the second kind. Considering that $Z_{0}(0)$ should be bounded, but

$$
N_{n}(0)=\infty, \text { so } c_{3}=0
$$

From the boundary condition equations (1) $Z_{0}(l)=0$ can be got, then simplifying equation (7),

$$
J_{n}(k l)=0
$$

If $\mu_{n m}$ is the m-th positive zero point of Bessel functions of the first kind, $k_{n m}=\frac{\mu_{n m}}{l}$ is the eigenvalue of equation (8), therefore, the eigenfrequency of membrane can be written in the form

$$
\omega_{n m}=\mu_{n m} \frac{V}{l}
$$

The mode of vibration corresponding to $\omega_{n m}$ can be expressed as

$$
Z_{n m}(r, \theta)=J_{n}\left(\mu_{n m} \frac{r}{l}\right) \sin (n \theta+\varphi)
$$

$$
J_{n}\left(\mu_{n m} \frac{r}{l}\right) \text { corresponds to the nodal diameter of }
$$

the membrane; $\sin (n \theta+\varphi)$ corresponds to the nodal circle of the membrane. The combination of nodal diameter and nodal circle of the membrane can describe the shape of a vibrating circular membrane surface.

If the radius is one, the solution type and normalization of $J_{n}\left(\mu_{n m}\right)$ are defined by its properties below. It is possible to define the function by its Taylor series expansion around $\mu_{n m}=0$ as

$$
J_{n}\left(\mu_{n m}\right)=\sum_{V=0}^{\infty}(-1)^{V} \frac{1}{V ! \Gamma(n+V+1)}\left(\frac{\mu_{n m}}{2}\right)^{n+2 V}
$$

yields

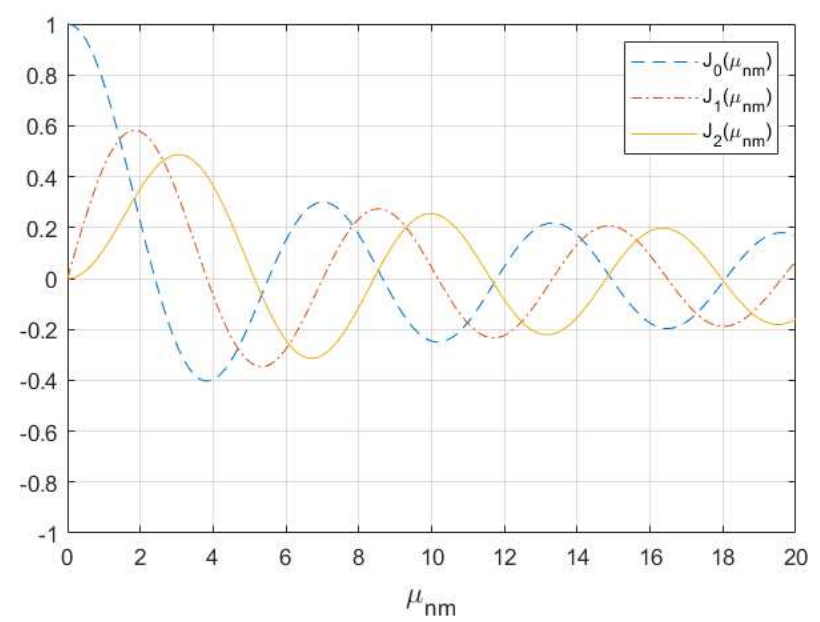

Fig. 4 Plot of Bessel functions of the first kind 
The first kind of Bessel functions as shown in Fig. 4, when the value of $\mu_{n m}$ becomes larger, $J_{n}\left(\mu_{n m}\right)$ shows the behavior of oscillation, it resembles the cosine or sine wave in shape; But the amplitude of the wave decays are similar to the negative power of $\mu_{n m}$.

Table 1 The first five zero points of $J_{0}(x), J_{1}(x)$ and $J_{2}(x)$

\begin{tabular}{rrrccc}
\hline $\mathrm{m}$ & 1 & 2 & 3 & 4 & 5 \\
\hline$\mu_{0 m}$ & 2.40483 & 5.52008 & 8.65373 & 11.7915 & 14.9309 \\
$\mu_{1 m}$ & 3.83171 & 7.01559 & 10.1735 & 13.3237 & 16.4706 \\
$\mu_{2 m}$ & 5.13562 & 8.41724 & 11.6198 & 14.7960 & 18.9801
\end{tabular}

For any shape of weld pool, the number of nodal circles in $\theta$ direction is $m$ and the number of nodal diameters in the direction of radius is $n$, which together determine the inherent oscillation mode of the weld pool.
This kind of simple standing wave, such as sine function and cosine function, will produce a variety of waveforms as shown in Table 2. The four common oscillation modes are $(0,1),(1,1),(2,1)$ and $(0,2)$ modes.

Table 2 Four common modes of circular membrane vibration

\begin{tabular}{|c|c|c|c|c|}
\hline & $(0,1)$ & $(1,1)$ & $(2,1)$ & $(0,2)$ \\
\hline \multicolumn{5}{|c|}{ 2-D image } \\
\hline \multicolumn{5}{|c|}{ 3-D image } \\
\hline \multirow[t]{9}{*}{ feature } & Upper and lower & Vibration of left and & The vibration of the & The center and the \\
\hline & vibrations with the & right antinodes & opposite antinode in & outer edge of the \\
\hline & center of the membrane & separated by one & the same direction and & membrane vibrate \\
\hline & as the antinode. & diameter node passing & the adjacent antinode in & backwards with the \\
\hline & & through the center of & the opposite direction, & largest antinode at the \\
\hline & & the membrane & which is divided by & center of the membrane \\
\hline & & & two diameter nodes & \\
\hline & & & passing through the & \\
\hline & & & center of the membrane & \\
\hline
\end{tabular}

The natural frequency of the weld pool can be expressed as

$$
\omega_{0}=k_{n m 0} \frac{\sqrt{c}}{R}
$$

The diffusion coefficient $c$ is closely related to the surface tension, gravity, geometric size of the pool and whether the pool is penetrated or not.

The vibration of the weld pool can be divided into three responses according to the internal and external initial conditions: 1. Zero input response, no external 
force applied, and the vibration of an initial position on the surface of the pool; 2. Zero state response, the initial state of the pool is zero, the force exerted by the outside, also known as forced vibration; 3. Full state response, has both initial state and external force exerted.

When the source term of the two-dimensional wave equation (2) is not zero, it represents forced vibration of the pool, such as the periodic external force

$$
f=\mathrm{A} \cos (\omega t)
$$

where $A$ is the amplitude, $\omega$ is the angular frequency, $t$ is time. When the source term is added, the typical stationary pool oscillation in time domain will appear.

When the weld pool grows to a certain size, the inherent oscillation frequency of weld pool changes to be equal to the sinusoidal frequency in the variable current, and the pool resonates at this time ${ }^{[28]}$. In the simulation, it is found that when the pool reaches the resonance point, the pool gradually leaves the resonance point, and the pool oscillation slows down gradually. This is the rapid release of system energy after the oscillation of the pool, leading to the departure from the resonance point. It has been proved that the frequency of the resonance point corresponds strictly to the size of the pool. The main frequency of pool oscillation is the same as that of metal transition. This is similar to forced vibration in vibration [29].

\section{Modeling simulation and results}

\subsection{Modeling}

The structure laser reflection imaging simulation system is constructed in COMSOL as shown in Fig. 5, and ray tracing technology in geometrical optics module is used to accurately trace ray.

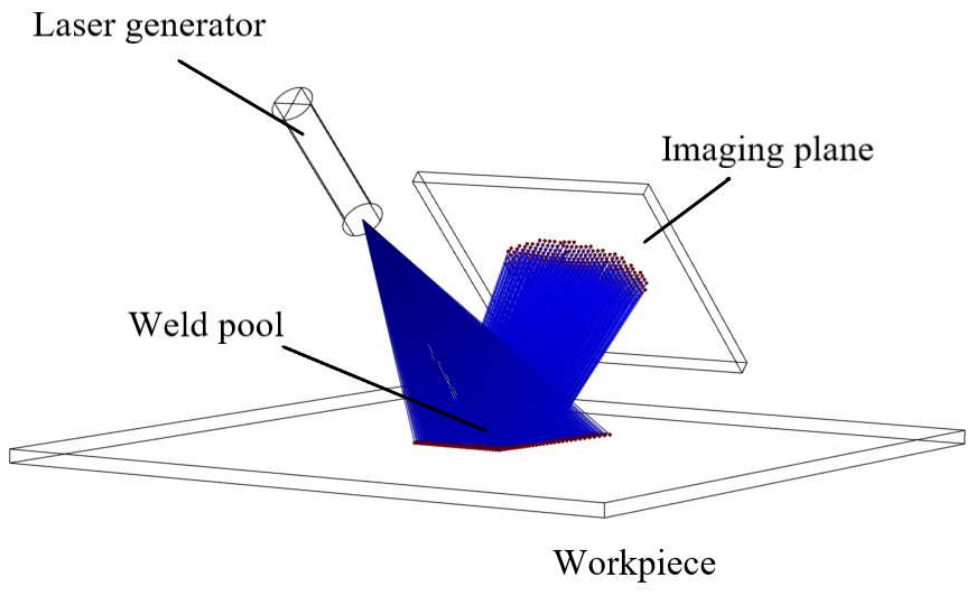

Fig. 5 Integrated pool simulation platform

The principle is as follows: first, according to the state of the weld pool, geometric size and the properties of liquid metals, a mathematical model of the wave equation is established in the mathematical interface according to equation (2). Then set the source item and make its frequency greater than or equal to the eigenfrequency of the weld pool. Doing transient simulation to find and export pool oscillation 3D grid file for desired mode. Second, opening the "geometric optics" module to mesh the pool and the imaging plane. Third, the laser generator is composed of a 30x30 laser dot matrix formed by "grid release" technology, and the light emitted is irradiated to the weld pool. The reflected laser is "frozen" when it reaches the imaging plane, and a built-in virtual camera can be used to take three-dimensional lattice images of the weld pool.

Test on convex, concave and plane respectively, and the simulation parameters and results are shown in Table 3 . 
Table 3 Simulation parameters and results

\begin{tabular}{|c|c|c|c|c|}
\hline & $\operatorname{radius}(\mathrm{mm})$ & height(mm) & model & simulation \\
\hline concave & 2.1 & -0.06 & & mIIIII!I! \\
\hline plane & 2.1 & 0 & & \\
\hline Convex & 2.1 & 0.06 & & \\
\hline
\end{tabular}

The simulation shows that when the structure laser is reflected to the concave, the distance between the points becomes smaller due to the focus, the diameter of the imaging plane becomes smaller. Because of the scattered light on the convex surface, the distance between the points becomes larger, the diameter of the imaging plane becomes larger.

No matter how the curvature changes, the number of points reflected to the imaging plane will not change. This means that the number of points is related to the diameter, and the surface shape can be analyzed through the lattice image.

By using mathematical modeling analysis method, the relevant physical properties of metal materials can be built into the software, which can greatly improve the efficiency and accuracy of simulation. The mainstream structural light analysis method and numerical simulation method are organically combined. The complex process in the weld pool can be visualized by the structural laser measurement technology. The simulation of the process can greatly reduce all kinds of errors and uncertainties in the test, facilitate the further improvement of the defects in the measurement method, optimize the equipment configuration, give full play to the potential and advantages of the structural laser method, capture the dynamic details of the weld pool oscillation process, and further carry out the basic research work of welding technology, so as to effectively control and improve the welding quality.

\subsection{Results}

Using high speed camera to capture the oscillation mode of weld pool surface under periodic external force, and compare the image with the simulation results.

\subsubsection{The $(0,1)$ mode}

The $(0,1)$ mode corresponds to the first zero point of 0-order Bessel function, which has two states: convex and concave. The maximum amplitude is in the middle of the weld pool, as shown in Fig. 6a-l. The spacing between the center of the dot matrix is looser than the edge, the image's horizontal and vertical dimensions are close to each other, indicating that the pool is convex; The middle of dot matrix is close, the edge spacing is loose, and the image's horizontal dimension is larger than the vertical dimension, indicating that the pool is concave. When the convex curvature is large, the lattice is loose; When the concave curvature is large, the lattice is tight. The period of variation is about $60 \mathrm{~ms}$, which indicates that the pool is in the attenuated oscillation state of $(0,1)$ mode. 


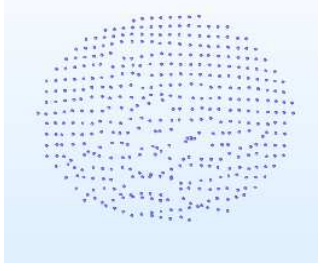

(a) $526 \mathrm{~ms}$

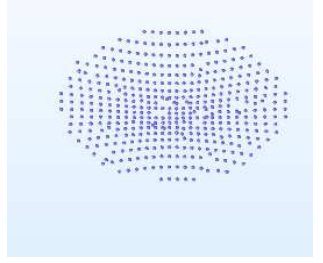

(e) $618 \mathrm{~ms}$

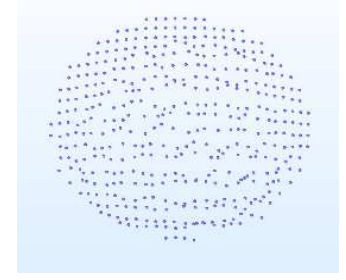

(i) $740 \mathrm{~ms}$

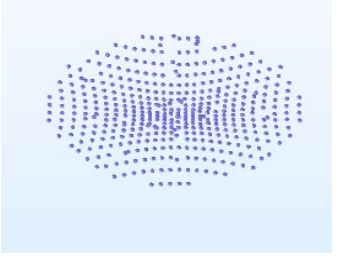

(b) $552 \mathrm{~ms}$

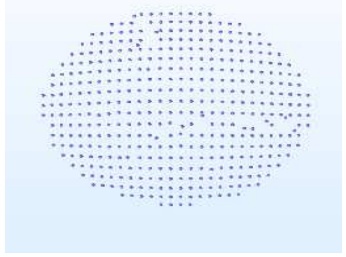

(f) $676 \mathrm{~ms}$

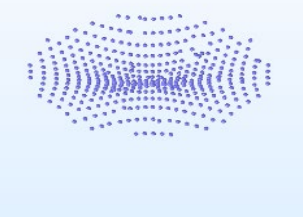

(j) $752 \mathrm{~ms}$

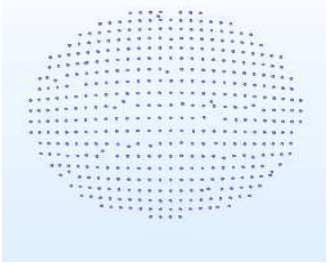

(c) $560 \mathrm{~ms}$

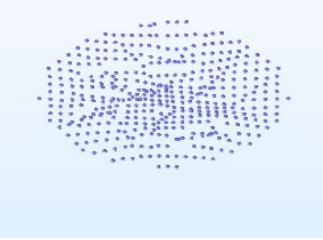

(g) $684 \mathrm{~ms}$

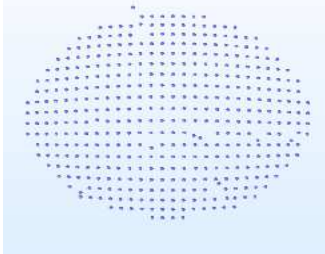

(k) $814 \mathrm{~ms}$

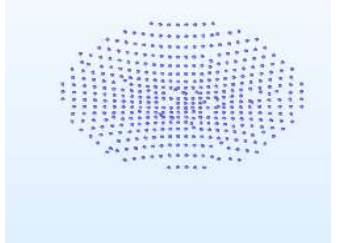

(d) $610 \mathrm{~ms}$

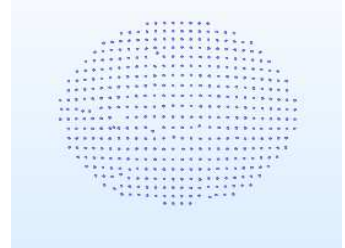

(h) $736 \mathrm{~ms}$

Fig. $6(0,1)$ Mode laser dot matrix image

The images of the reflective laser grid on the surface of the weld pool were collected by experiment, as shown in Fig. 7. The experimental results are consistent with the simulation results in Fig. 6. By the comparison with

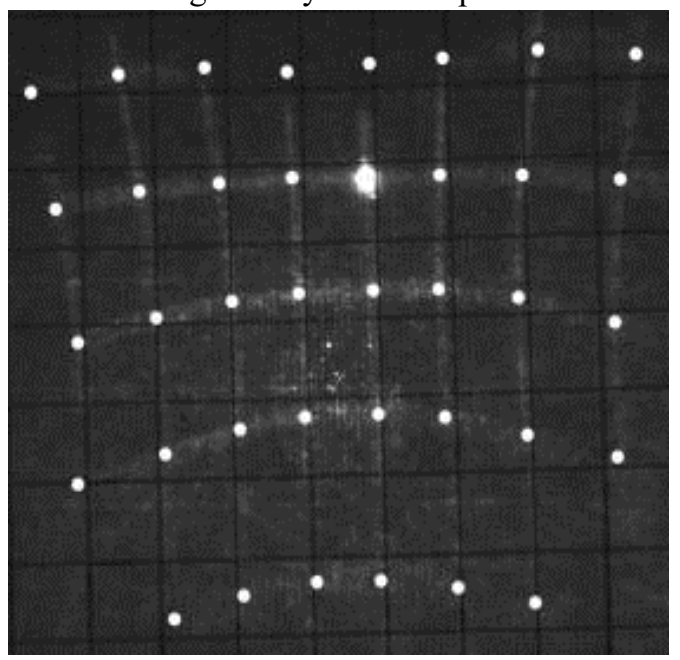

(a) simulation result of weld pool surface, Fig. 7 shows the oscillation mode of GTA weld pool is $(0,1)$ mode. Fig. 7a shows the weld pool surface is convex. Fig. $7 \mathrm{~b}$ shows the weld pool surface is concave.

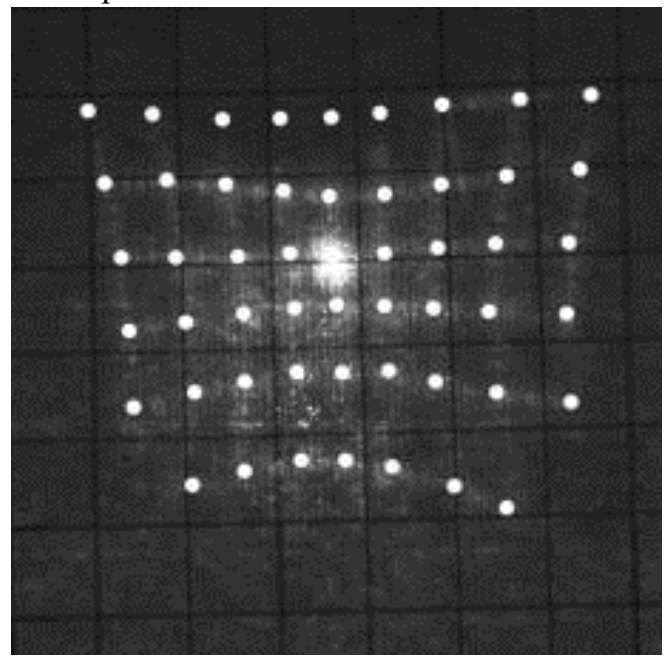

(b)

Fig. $7(0,1)$ mode experiment results

\subsubsection{The $(1,1)$ mode}

The $(1,1)$ mode corresponds to the first zero point of 1-order Bessel function. The features of Fig. 8a-1 are that one direction of the dot matrix has loose spacing, occupies a larger area, the other direction has close spacing, occupies a smaller area. The loose and large side of the dot matrix indicates that the weld pool is convex, 
and the opposite direction indicates that the weld pool is concave. Over a period of time, the direction of scattering is exchanged with that of the compact location, and the period of change is about $32 \mathrm{~ms}$. The area

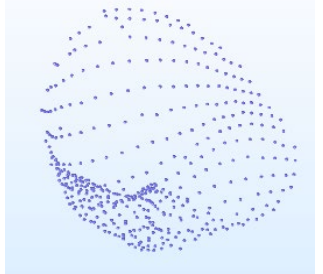

(a) $160 \mathrm{~ms}$

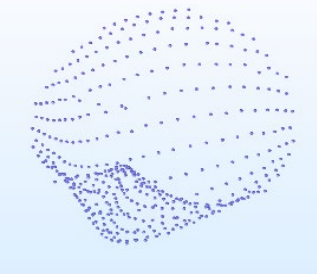

(e) $228 \mathrm{~ms}$

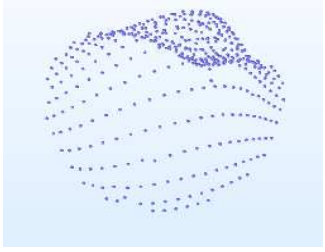

(i) $262 \mathrm{~ms}$

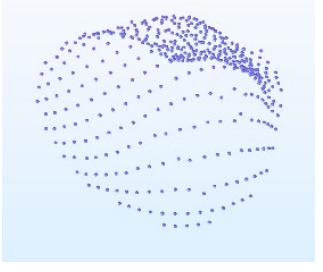

(b) $164 \mathrm{~ms}$

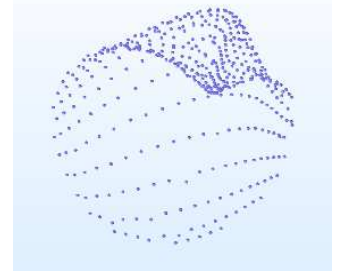

(f) $232 \mathrm{~ms}$

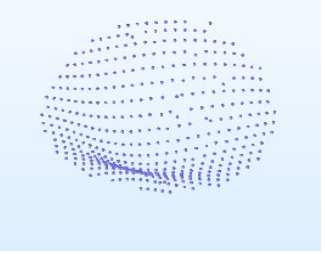

(j) $268 \mathrm{~ms}$ occupied by the lattice is gradually smaller compared with the lattice divergence, indicating that the pool is in the attenuated oscillation state of $(1,1)$ mode.

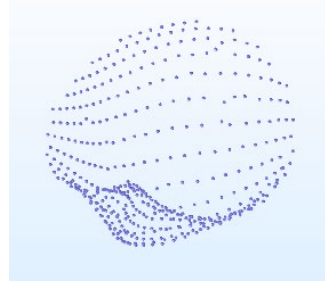

(c) $192 \mathrm{~ms}$

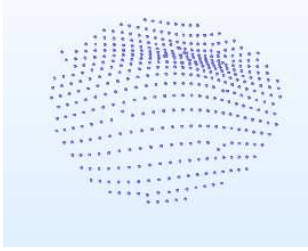

(g) $236 \mathrm{~ms}$

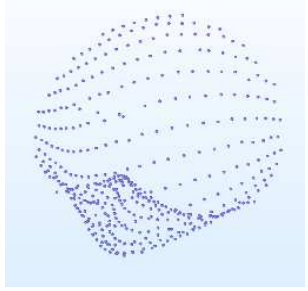

(k) $288 \mathrm{~ms}$ (d) $196 \mathrm{~ms}$

(h) $258 \mathrm{~ms}$
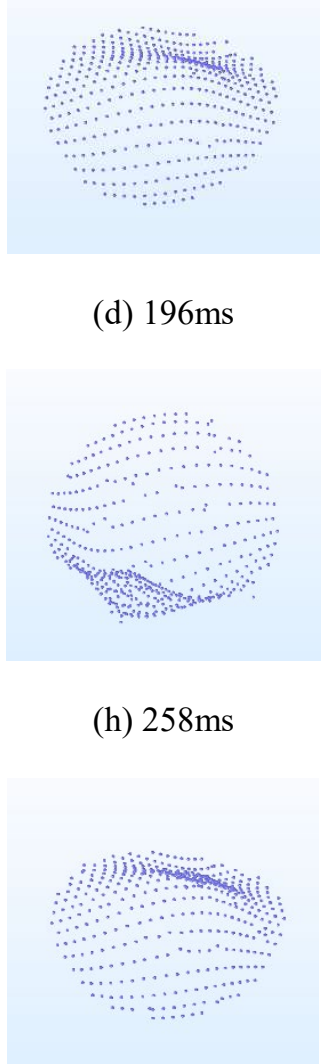

(1) $294 \mathrm{~ms}$

Fig. $8(1,1)$ Mode laser dot matrix image

Under the action of pulse current, when the penetration critical penetration is reached, sloshing oscillation can be observed, and the image of continuous

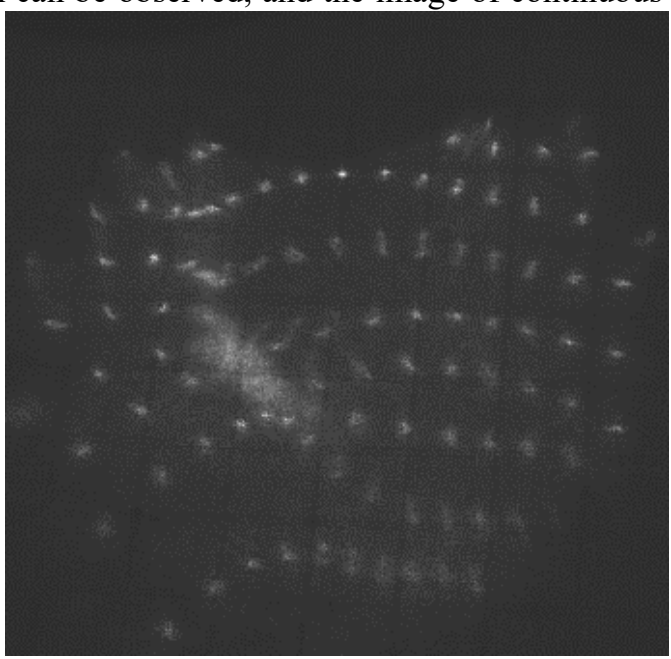

(a) reflection laser dot matrix is shown in Fig. 9. This is consistent with the simulation in Fig. 8.

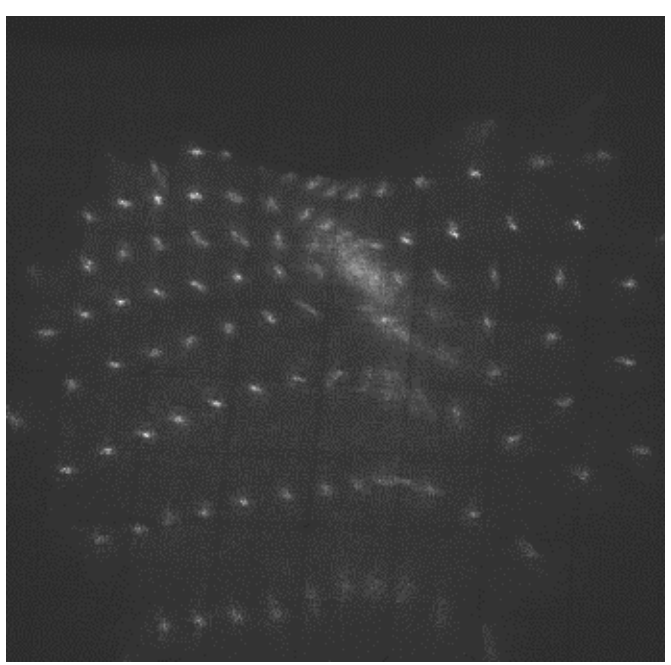

(b)

Fig. $9(1,1)$ mode experiment results

\subsubsection{The $(2,1)$ mode}

The $(2,1)$ mode corresponds to the first zero point of 2-order Bessel function. As is shown in Fig 10a-1, the spacing between the two sides of the lattice is loose, 
showing an irregular circle. A narrow and close lattice is in the middle as the dividing line. A close lattice at both ends of the dividing line shows an irregular triangle area. After a period of time, the dividing line is perpendicular to the original position, and the position of the close triangle area becomes a loose quasi circle, and then it changes back. The period of variation is about $8 \mathrm{~ms}$, which indicates that the weld pool is in the state of $(2,1)$ mode rapid oscillation attenuation.

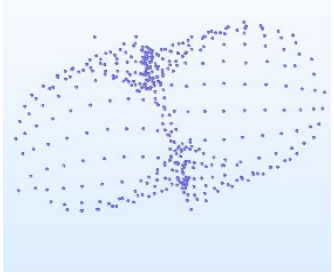

(a) $188 \mathrm{~ms}$

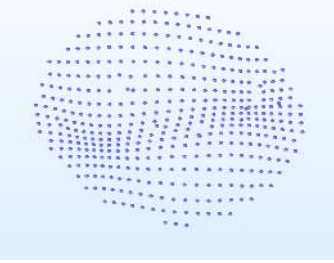

(e) $232 \mathrm{~ms}$

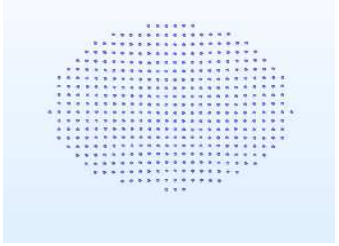

(i) $302 \mathrm{~ms}$

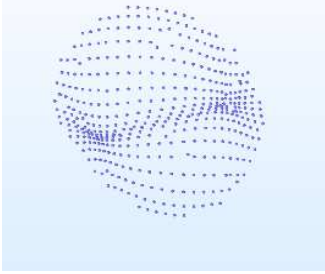

(b) $190 \mathrm{~ms}$

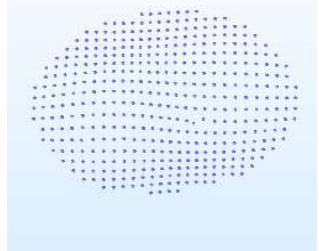

(f) $236 \mathrm{~ms}$

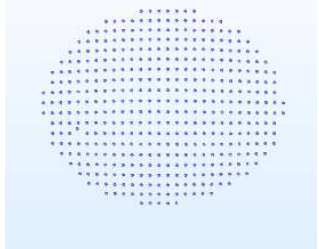

(j) $354 \mathrm{~ms}$

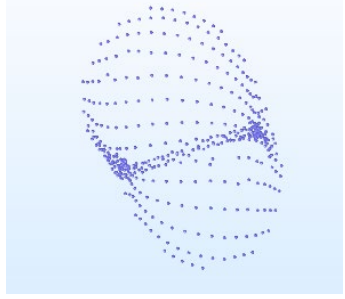

(c) $192 \mathrm{~ms}$

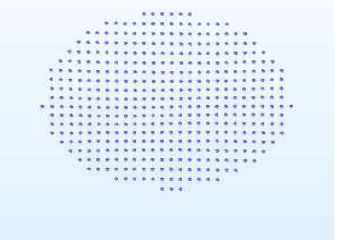

(g) $242 \mathrm{~ms}$

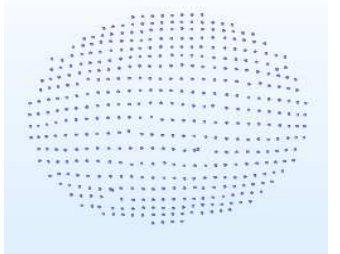

(k) $420 \mathrm{~ms}$

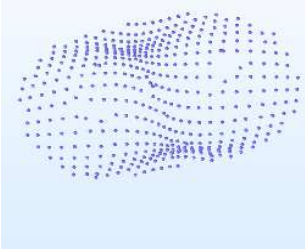

(d) $196 \mathrm{~ms}$

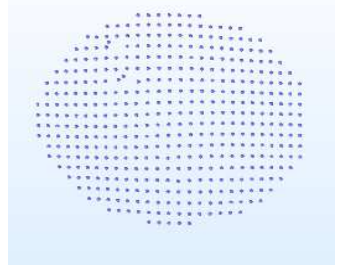

(h) $296 \mathrm{~ms}$

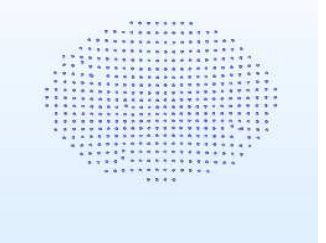

(1) $430 \mathrm{~ms}$

Fig. $10(2,1)$ mode laser dot matrix image

The reflective image collected in the pulsed GTA welding experiment as shown in Fig. 11, its surface

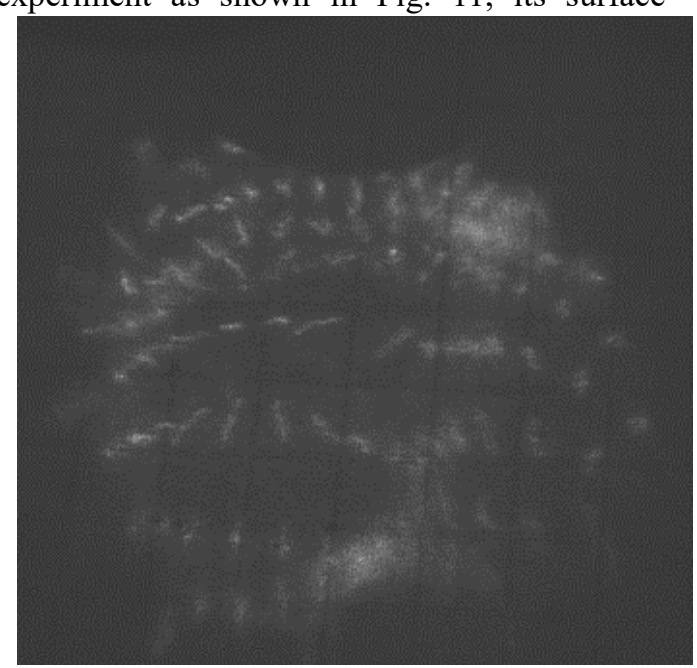

(a) oscillation mode matches the simulation results of Fig. 10.

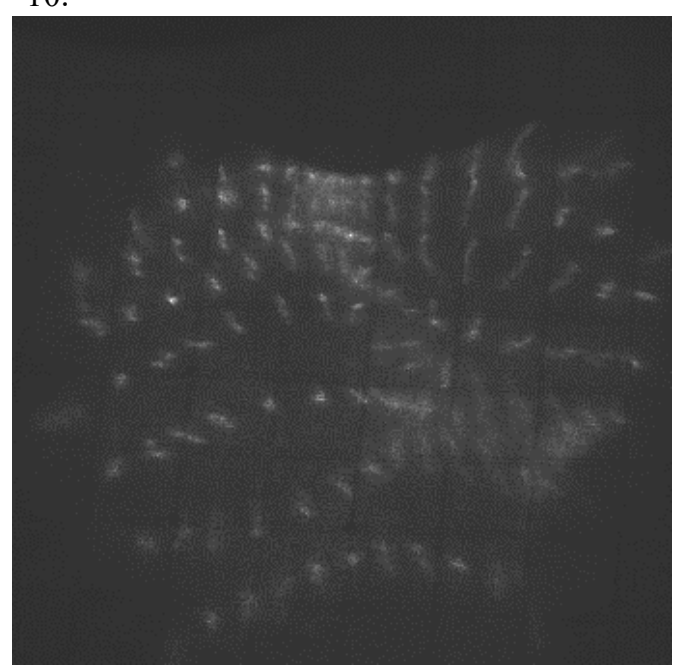

(b)

Fig. $11(2,1)$ mode experiment results 


\subsubsection{The $(0,2)$ mode}

The $(0,2)$ mode corresponds to the second zero point of 0-order Bessel function. As is shown in Fig12(a)-(1), the lattice spacing in the middle core area is close, and the outer core area is loose. The lattice spacing

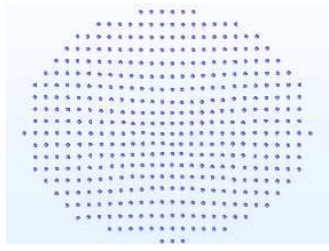

(a) $132 \mathrm{~ms}$

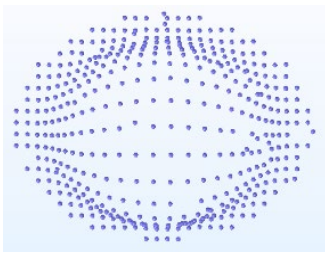

(e) $137 \mathrm{~ms}$

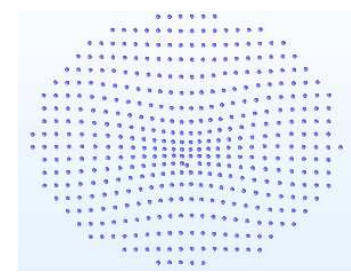

(i) $173 \mathrm{~ms}$

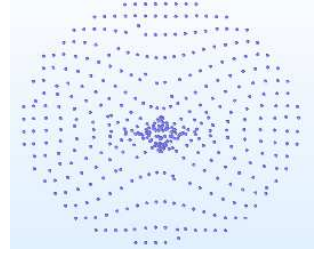

(b) $133 \mathrm{~ms}$

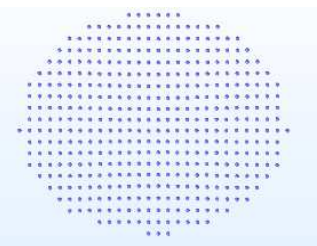

(f) $139 \mathrm{~ms}$

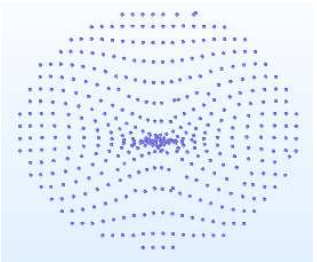

(j) $174 \mathrm{~ms}$

in the middle large area is loose, and there is a narrow and compact circle of lattice near the outer edge. The period of variation is about $7 \mathrm{~ms}$, which indicates that the pool is in a fast attenuated oscillation state of $(0,2)$ mode.

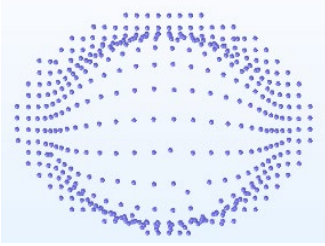

(c) $135 \mathrm{~ms}$

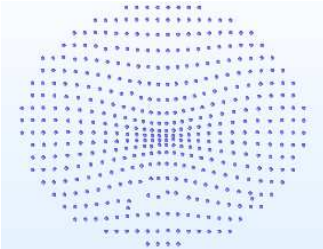

(g) $140 \mathrm{~ms}$

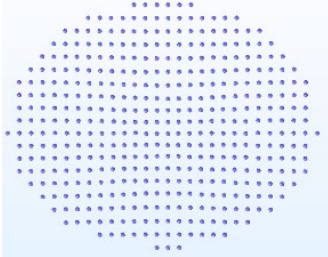

(k) $177 \mathrm{~ms}$

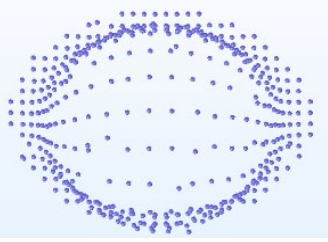

(d) $136 \mathrm{~ms}$

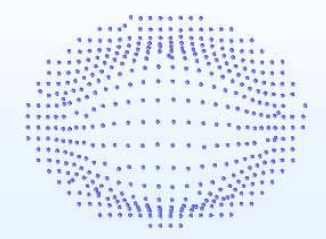

(h) $171 \mathrm{~ms}$

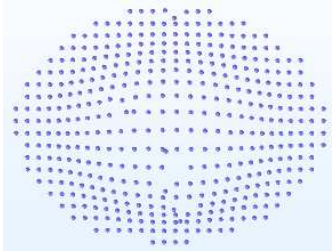

(1) $215 \mathrm{~ms}$

Fig. $12(0,2)$ mode laser dot matrix image

The oscillation of weld pool in full penetration is also radially symmetric with respect to the arc axis. The pool oscillation as shown in Fig. 13 can be clearly seen

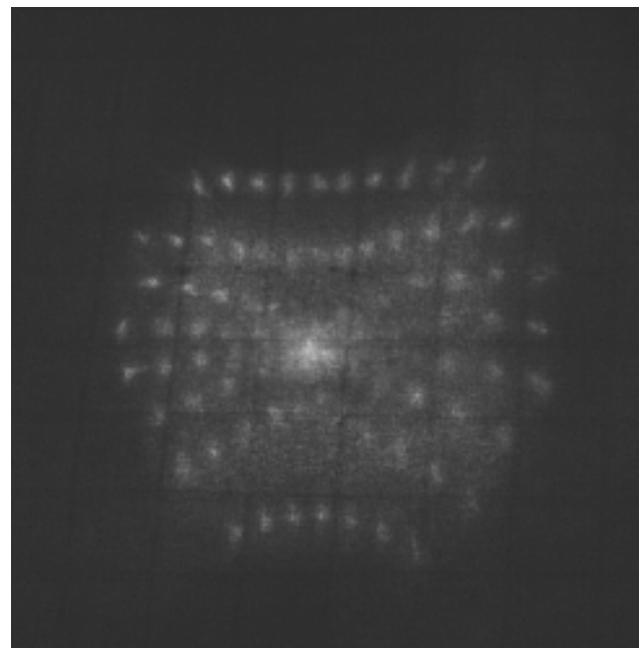

(a) from the reflected laser point characteristics, which is consistent with the simulation results in Fig. 12.

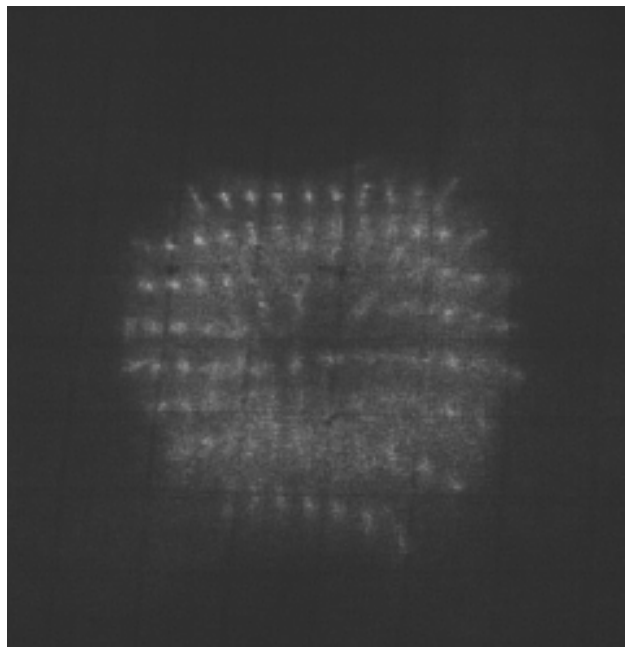

(b)

Fig. $13(0,2)$ mode experiment results

To obtain more characteristics of the weld pool oscillation surface shape, scholars have carried out 
further research on the pool shape under direct current and pulsed current.

\subsection{The weld pool shape under direct current}

\section{(DC) and pulsed GTA welding}

In order to study the behavior under stationary DC GTA welding, as shown in Fig. 2, the height of the upper and lower surfaces of the GTA welding pool changes with time. At the beginning of welding, the upper surface of the melting pool is heated, melted and expanded, which becomes convex due to the effect of the liquid surface tension. The lower surface does not change. At $3.9 \mathrm{~s}$, the weld pool becomes wider, the workpiece is penetrated. The upper and lower free surfaces fall under the action of gravity. From $5 \mathrm{~s}$ to $5.5 \mathrm{~s}$, the change of the upper surface is very obvious, from convex to concave. Compared with the change of the upper surface, the change of the lower surface is not obvious. The change of the lower surface increases first and then decreases. After that, when the welding time reaches $7.5 \mathrm{~s}$, the variation of the upper and lower surfaces basically reaches the same value. After that, the variation of the height of upper surface is not obvious, but the variation of the lower surface is extremely large.

Explanation of the above phenomenon: in the first stage, the volume and depth of the weld pool are smaller. Therefore, the effect of surface tension is greater than the gravity and arc pressure on weld pool. The weld pool is convex and belong to the $(0,1)$ mode. The second stage, as the welding goes, the temperature in the work-piece gradually increases and the range of the temperature field becomes larger and both the penetration depth and melting width increase, the free surface is deformed more with the welding time. Due to the arc pressure, the center of the weld pool gradually changes from convex to concave, the liquid metal expands radially, so it presents a concave image of $(0,2)$ mode. In the third stage, the weld pool is penetrated, the bottom of weld pool is no longer under pressure, and gravity is the main force. The

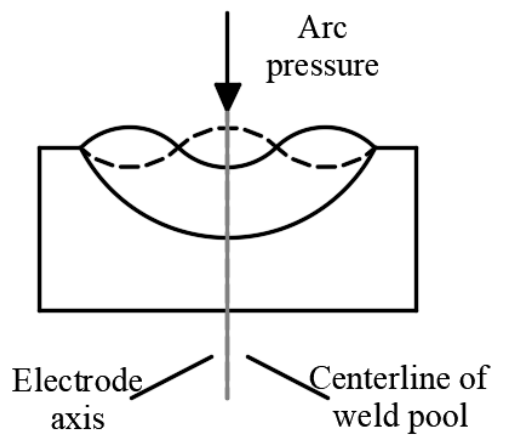

(a)

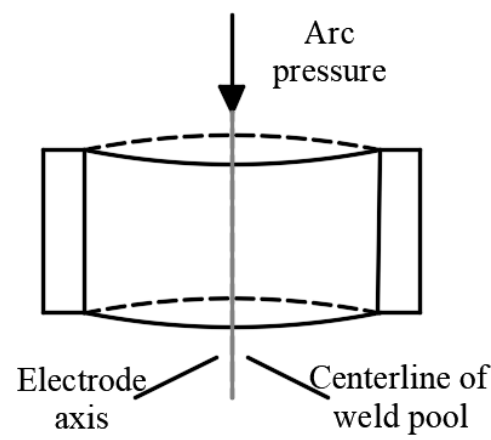

(b) liquid metal sags to a concave surface in the form of $(0,1)$ mode. The shape of the whole weld pool is central symmetrical with respect to the torch, and its laser dot matrix image is stable and clear. These three stages are developed dynamically in seconds, so the laser lattice image is clearly recognizable. $(2,1)$ or $(1,1)$ mode can also occur when the current or speed of a welding suddenly changes.

In pulsed GTA welding, when the peak current is applied, the width and depth of weld pool increases steeply during the peak current period [30], the lattice is fuzzy and gathered together, indicating that the surface of the weld pool is concave. When the base current is applied, the laser grid changes from converging to diverging, which indicates that the surface of the weld pool is convex, but the surface of the weld pool is still fluctuating.

\subsection{The relationship and difference between}

\section{the DC and pulsed GTA welding}

During the stationary welding process, as shown in Fig. 14a, the electrode axis coincides with the centerline of the weld pool, and the arc is located exactly at the weld pool center. When the liquid metal is supported by the bottom of the weld pool, the weld pool center is symmetrically depressed under the arc pressure, and the liquid metal is pushed radially. Hence the pool edge is raised, and the weld pool is similar to $(0,2)$ Mode; When the bottom of the weld pool loses solid metal support as shown in Fig. 14b, the liquid metal at the pool bottom is maintained by the surface tension. Due to the arc pressure and the lack of solid metal support at the bottom, the upper and lower surfaces of weld pool are in a concave state, which is similar to the $(0,1)$ mode. This is consistent with the research conducted by $\mathrm{K}$. Zhang et al. [31]

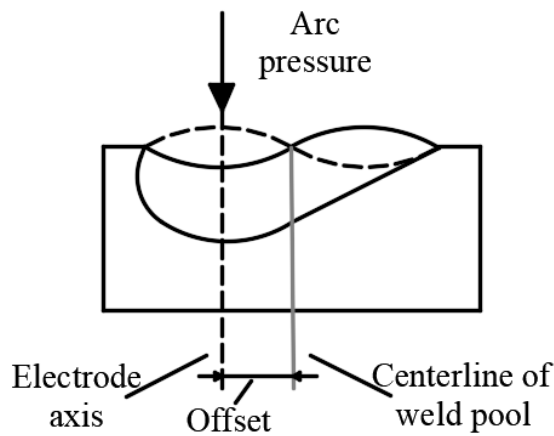

(c)

Fig. 14 Different shapes of weld pool surface during welding process

In most cases, when there is an offset between the centerline of weld pool and the electron axis as shown in
Fig $14 \mathrm{c}$, the metal in the weld pool is easily pushed to the rear part of the weld pool, which resulted in an evident 
asymmetrical shape of weld pool ${ }^{[32]}$. It can be represented by $(1,1)$ mode.

When the current of the torch is suddenly reduced, the arc pressure at the top of the weld pool is released. The lowest point of the pool surface stretches upward due to surface tension. The shape of the corresponding weld pool oscillating surface is convex, and the original protrusion changes to the opposite direction. The shape of the pool surface changes as shown by the dashed line in Fig. 14a-c.

The behavior of weld pool under GTA welding is a dynamic evolution process. The final surface shape depends on the surface tension, gravity, the support force of the weld pool wall and the applied arc pressure. Under the joint action of these factors, it determines whether the pool is in a quasi-steady state or a dynamic process. When the weld pool is depressed, the point matrix aggregates; otherwise, the point matrix diverges. By calculating the time interval between two aggregated or divergent laser lattice images, the oscillation period in pool can be obtained ${ }^{[33]}$.

The difference between the DC and pulsed GTA welding: in the case of DC welding, from the beginning to the penetration, if the welding conditions remain unchanged, the shape of pool surface will change non-periodically, lasting several seconds, and the dot matrix image is clear; in the case of pulse welding, the shape of the weld pool surface changes periodically, lasting several milliseconds to several hundred milliseconds, and the image is slightly blurred.

However, when DC welding conditions are abrupt, DC welding and pulsed welding can be converted to each other. If the current and speed change sharply, the weld pool will have short-term periodic changes and the dot matrix image will be blurred for a short time.

\subsection{Characteristic of the weld pool surface}

Different mathematical models have been developed to describe the vibration modes of the weld pool, as shown in Table 4. The reflection changes of laser lattice reflect the dynamic changes of weld pool surface. Three modes of oscillation can be clearly observed under different penetration. The oscillation mode can be described by the first Bessel function, which is consistent with the experimental results.

Table 4 Mode shapes of weld pool obtained by different scholars

\begin{tabular}{|c|c|c|c|c|}
\hline & $(0,1)$ & $(1,1)$ & $(0,2)$ & $(2,1)$ \\
\hline$k_{n m}$ & $\frac{4.80}{D}$ & $\frac{7.66}{D}$ & $\frac{11.04}{D}$ & $\frac{10.28}{D}$ \\
\hline shapes & & & & \\
\hline $\begin{array}{l}\text { Xiao and den Ouden } \\
\qquad\left(1990^{[34]}\right)\end{array}$ & $\sqrt{ }$ & - & $\sqrt{ }$ & - \\
\hline ZHANG Shiqi(2016 $\left.{ }^{[35]}\right)$ & $\sqrt{ }$ & $\sqrt{ }$ & - & - \\
\hline Kristinn Andersen $\left(1997^{[36]}\right)$ & $\sqrt{ }$ & $\sqrt{ }$ & $\sqrt{ }$ & - \\
\hline C.D. Sorensen $\left(1990^{[37]}\right)$ & - & - & $\sqrt{ }$ & - \\
\hline AENDENROOMER(1998 $\left.{ }^{[38]}\right)$ & $\sqrt{ }$ & - & $\sqrt{ }$ & - \\
\hline Jianbin J(2004 $\left.{ }^{[39]}\right)$ & $\sqrt{ }$ & $\sqrt{ }$ & - & - \\
\hline
\end{tabular}

It can be seen that there is a one-to-one relationship among the shape, eigenvalue $k_{n m}$ and mode shape of the lattice images. However, the pool oscillation model observed by scholars is limited to a few types, especially $(2,1)$ model is rarely studied. The reason should be limited by experimental parameters and equipment 
conditions. It can be seen that numerical simulation is very necessary in the field of welding. It can accurately explain the various vibration phenomena that may be encountered in the welding process.

\section{Conclusion}

In this paper, the oscillation modes of weld pool were analyzed based on Bessel equation, and the three-dimensional images of common in weld pool were simulated. The laser dot matrix images of $(0,1),(1,1),(2$, $1),(0,2)$ oscillation modes at different times were obtained by structured laser optical measurement simulation. The oscillation mode of stationary GTA weld pool was analyzed based on laser dot matrix images. The following conclusions can be obtained in this work:

1) The status of the weld pool can be judged based on laser dot matrix images. For example, by distinguishing the distribution of concave, convex and flat surfaces, we can see the oscillation mode and oscillation frequency of the pool, thus distinguishing the pool from the non-penetrating or penetrating states.

2) In stationary DC GTA welding, the oscillation mode generally is $(0,1),(0,2)$ mode. In pulsed GTA welding process, the arc impact on the weld pool during peak current phase will cause high frequency oscillation on the surface of the pool, which causes great distortion on the surface of the pool, resulting in $(1,1),(2,1),(0,2)$ oscillation mode.

3) Although the laser dot matrix images on the imaging plane is ever-changing, the shape of the weld pool can be recognized based on laser dot matrix image. The denser the dot matrix emitted by the laser generator, the higher the measurement accuracy. This is also one direction for improving structural laser technology.

\section{Declaration}

\section{Ethics approval and consent to participate}

The manuscript is ethically approved and all authors agree to participate.

\section{Publication}

The authors all agree to publish.

\section{Availability of data and materials}

All authors promise that materials and data are authentic.

\section{Authors' Contributions}

WU Xingpei study the welding process by COMSOL and wrote the manuscript; HUANG Jiankang and FAN Ding propose the research project, and conceived and designed the study and revised the manuscript; HE Jing improve the research by theory and revised the manuscript; LIU Shien and LIU Guangyin assisted in numerical analysis and experimental verification. All authors read and approved the final manuscript.

Competing Interests
The authors declare no competing financial interests.

\section{Biographical notes}

$\mathrm{Wu}$ Xingpei, is a currently student in Lanzhou University of Technology, China. His research interests include numerical simulation of welding process.

E-mail: 1409456083@qq.com

HUANG Jiankang, is currently an associate professor in Lanzhou University of Technology, China. His research interests include numerical simulation of welding and arc additive manufacturing.

E-mail:sr2810@163.com

HE Jing, is a faculty in Southern University of Science and Technology, China. His research interests include welding process and additive manufacturing.

E-mail: hejing0229@gmail.com

LIU Shien, is a currently student in Lanzhou University of Technology, China. His research interests include dissimilar metal connection and arc additive manufacturing.

E-mail: 18894007605@163.com

LIU Guangyin, is a currently student in Lanzhou University of Technology, China. His research interests include dissimilar metal connection and numerical simulation of welding.

\section{E-mail: 15023860381@163.com}

FAN Ding, is currently a professor in Lanzhou University of Technology, China. His research interests include numerical simulation of welding and arc additive manufacturing.

E-mail: fand@lut.cn;

\section{Acknowledgements}

We are grateful for the technical and financial support provided by Lanzhou University of Technology, National Natural Science Foundation of China.

\section{Funding}

This work was funded by National Natural Science Foundation of China (No. 51205197).

\section{References}

[1] M. Kanouff, R. Greif, The unsteady development of a GTA weld pool, International Journal of Heat \& Mass Transfer, 35 (1992) 967-979.

[2] H.S. Song, Y.M Zhang, Three-dimensional reconstruction of specular surface for a gas tungsten arc weld pool, Measurement Science \& Technology, 18 (2007) 3751-3767.

[3] Q.Y. Du, S.B. Chen, T. Lin, Inspection of weld shape based on the shape from shading, The International Journal of Advanced Manufacturing Technology, 27 (2006) 667-671.

[4] C.X. Zhao, I.M. Richardson, S. Kenjeres, C.R. Kleijn, Z. Saldi, A stereo vision method for tracking particle 
flow on the weld pool surface, Journal of applied physics, 105 (2009) 1-8.

[5] H. Park, S. Rhee, K. Um, Analysis of Weld Pool Flow and Shape Considering the Impact of Droplets in GMAW, Journal of Advanced Nursing, 16 (1998) 83-90.

[6] C.S. Wu, T. Zhang, Y.H. Feng, Numerical analysis of the heat and fluid flow in a weld pool with a dynamic keyhole, International Journal of Heat and Fluid Flow, 40 (2013) 186-197.

[7] Y. Satoshi, Y. Kensuke, O. Kenji, Numerical simulation of weld pool in narrow gap GMA welding, Quarterly Journal of the Japan Welding Society, 27 (2009) 506-516.

[8] C.S. Wu, Z.N. Cao, L. W, Numerical analysis of three-dimensional fluid flow and heat transfer in TIG weld pool with full penetration, Acta Metallurgica Sinica, 16 (1993) 894-895.

[9] P.K Palani, N. Murugan, Selection of parameters of pulsed current gas metal arc welding, Journal of Materials Processing Technology, 172 (2006) 1-10.

[10] Y.K. Liu, Y.M. Zhang, Control Engineering Practice Control Engineering Practice, 21 (2013) 1469 - 1480

[11] H.K. Narang, U.P. Singh, M.M. Mahapatra, P.K. Jha, Prediction of the weld pool geometry of TIG arc welding by using fuzzy logic controller, International Journal of Engineering, Science and Technology, 3 (2011) 77-85.

[12] J.S. He, W. Liu, B.G. Zhang, Q.S. Wu, Numerical simulation on the shape of liquid surface of TIG full-penetrated weld pool. Rare Metals, 26 (2007) 73-76.

[13] F. Lu, S. Yao, S. Lou, Y. Li, Modeling and finite element analysis on GTAW arc and weld pool, Computational Materials Science, 29 (2004) 0-378.

[14] S. Satonaka, Measurement of free surface of the weld pool by optical method and image analysis, Japan Welding Society, 2 (1984) 3-9.

[15] G Saeed, Y M Zhang, Weld pool surface depth measurement using a calibrated camera and structured light, Measurement Science and Technology, 18 (2007) 2570-2578.

[16] H. Maruo, Y. Hirata, Natural frequency and oscillation mode of weld pool, Japan Welding Society, 1992 50-54.

[17] W. Wang, Z. Wang, S. Hu, P, BAI, et al. Weld pool surface fluctuations sensing in pulsed GMAW, Welding Research, , 97 (2018) 327-337. DOI: doi.org/10.29391/2018.97.028

[18] Y. Hirata, S. Kunishige, T. Ohji, 3D numerical model of weld pool oscillation in GTA welding, Japan Welding Society, 73 (2003) 184-185.

[19] S.B. Chen, J. Wu, Modeling Methods of Weld Pool Dynamics During Pulsed GTAW, Intelligentized Methodology for Arc Welding Dynamical Processes, 2009 113-162

[20] Y.K. Liu, Y.M. Zhang, Dynamic control of 3D weld pool surface based on human response model, The International Federation of automatic control, 47 (2014) 10640-10645.
[21] W. Lu, Y.M. Zhang, Robust sensing and control of the weld pool surface, Measurement Science and Technology, 17 (2006) 2437 - 2446.

[22] C.D. Yoo, R.W. Richardson, An experimental study on sensitivity and signal characteristics of weld pool oscillation, Transactions of the Japan Welding Society, 24 (1993) 54-62.

[23] G. Saeed, M. Lou, Y.M. Zhang, Computation of 3D weld pool surface from the slope field and point tracking of laser beams, Measurement Science and Technology, 15 (2004) 389-403.

[24] X.W. Wang. Analysis and Modeling of GTAW Weld Pool Geometry, International Conference on Intelligent Computing for Sustainable Energy \& Environment, 355 (2013) 284-293.

[25] Y.K. Liu, Y.M. Zhang. Control of 3D weld pool surface, Control Engineering Practice, 21 (2013) 14691480 .

[26] H.S. Song, Y.M. Zhang, Image Processing for Measurement of Three-Dimensional GTA Weld Pool Surface. Welding Journal, 86 (2007) 323.s-330.s.

[27] L. Teich, A. Hütten, C. Schröder, Utilization of COMSOL Multiphysics' JAVA API for the Implementation of a Micromagnetic Modeling and Simulation Package with a Customized User Interface 2013.

[28] C.L. Yang, Detection of surface tension and effect of surface active flux in TIG welding, Chinese Journal of Mechanical Engineering, 36 (2000) 59-63.

[29] F. Wang, W.K Hou, S.X. Hu, Simulation system of gas shielded welding of melting electrode, Transactions of the china welding institution, 24 (2003) 35-39.

[30] W.H. Kim, S.J. Na, Heat and fluid flow in pulsed current GTA weld pool, International Journal of Heat and Mass Transfer, 1998,41 3213-3227

[31] K. Zhang, Y.M. Zhang, J.S. Chen, S.J. Wu, Observation and analysis of three-dimensional weld pool oscillation dynamic Behaviors, Welding research, 96 (2017) 143s-153s.

[32] C.K Li, Y. Shi, Y.F. Gu, P. Yuan, Monitoring weld pool oscillation using reflected laser pattern in gas tungsten arc welding, Journal of materials processing technology, 255 (2018) 1-19.

[33] J.K. Huang, M.H. Yang, J.S. Chen, F.Q. Yang, Y.M. Zhang, D. Fan, The oscillation of stationary weld pool surface in the GTA welding, Journal of Materials Processing Technology 2018 (256) 57-68.

[34] Y.H. Xiao, G.D. Ouden, A Study of GTA Weld Pool Oscillation, Welding Research Supplement, 1990, 289-293.

[35] S.Q. Zhang, S.S Hu, Z.J. Wang, Weld penetration sensing in pulsed gas tungsten arc welding based on arc voltage, Journal of Materials Processing Technology, 2016(229) 520-527.

[36] K. Andersen, G.E. Cook, Fellow, IEEE, R.J. Barnett, A.M. Strauss, Synchronous weld pool oscillation for monitoring and control, IEEE Transactions on Industry applications, 33 (1997) 464-471. 
[37] C.D. Sorensen, T.W. Eagar, Modeling of oscillations in partially penetrated weld pools, Journal of Dynamic Systems, Measurement, and Control, 112(1990) 469-474. [38] A.J.R Aendenroomer, G.D. Ouden. Weld Pool Oscillation as a Tool for Penetration Sensing during Pulsed GTA Welding, Welding Journal, 77 (1998) p.181s-187s.
[39] J. Jianbin, H. Hasegawa, Y. Suga, Oscillation of Molten Pool by Pulsed Assist Gas Oscillating Method and Penetration Control Using Peculiar Frequency, Journal of High Temperature Society, 30 (2004) 263-269. 
Figures
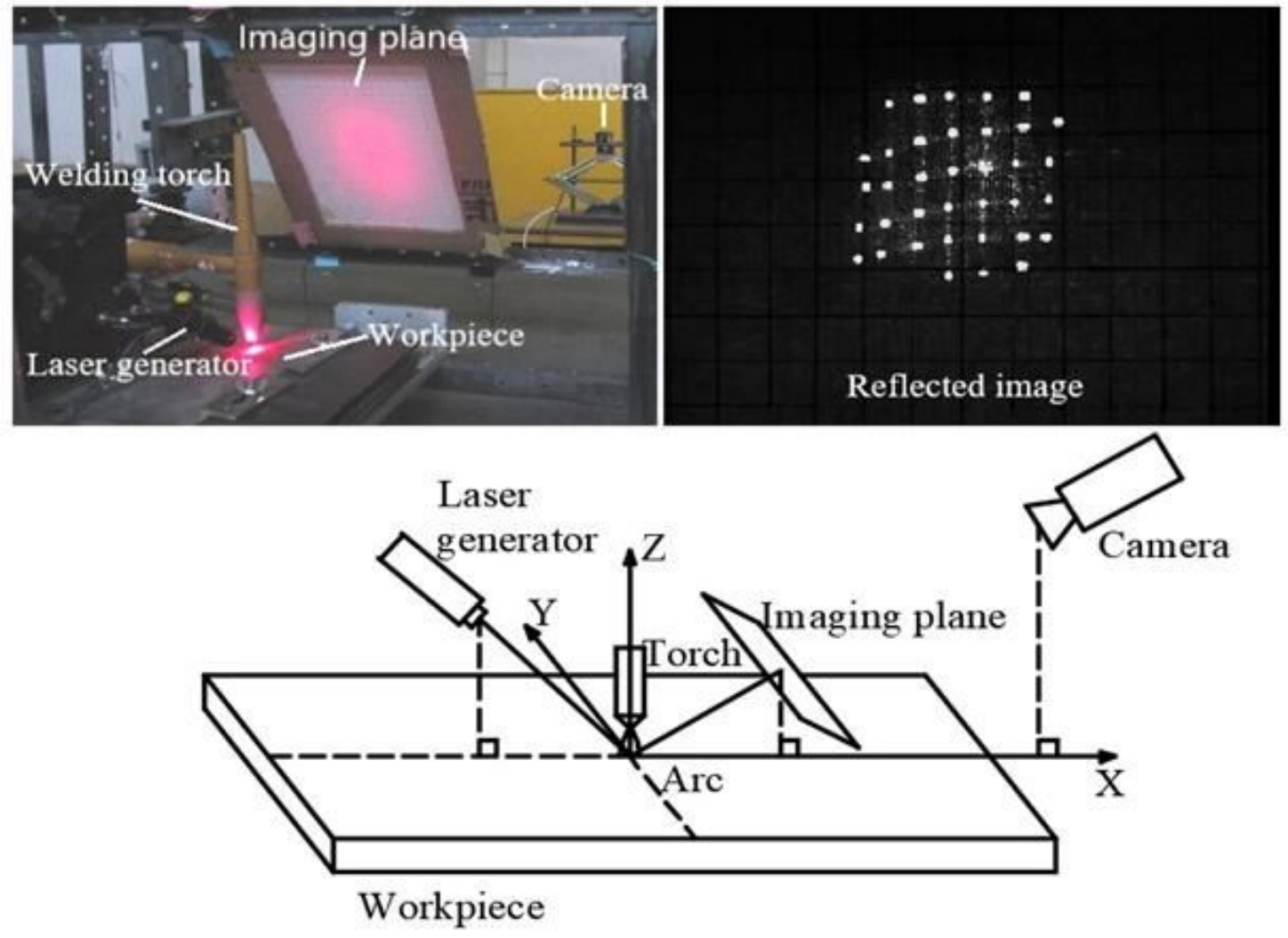

(a)

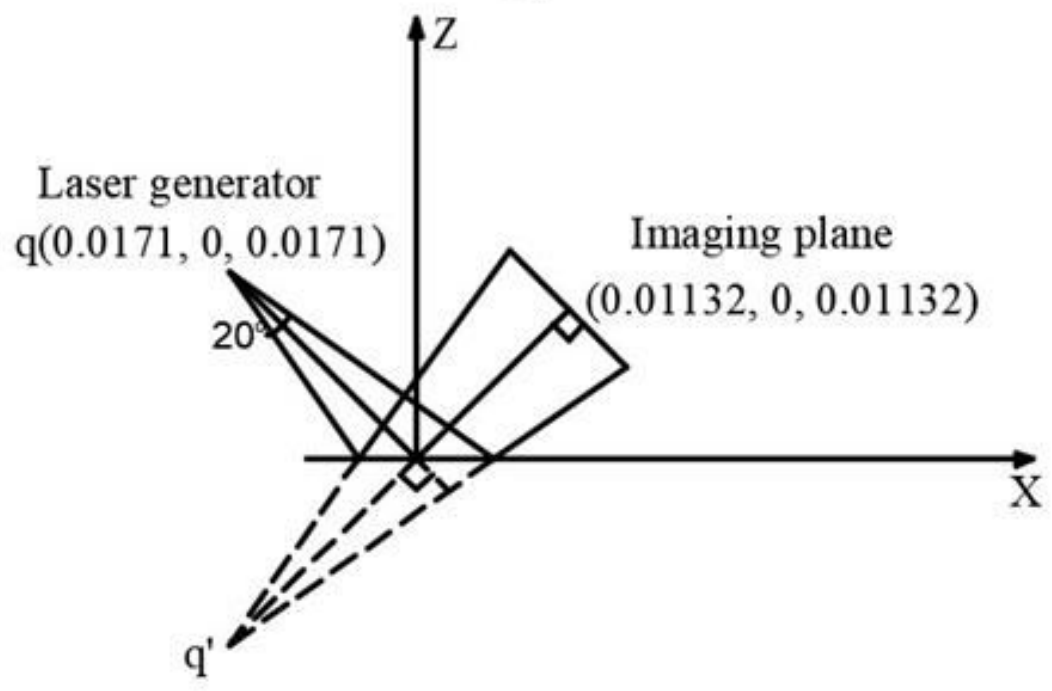

(b)

Figure 1

Schematic diagram of the test system 


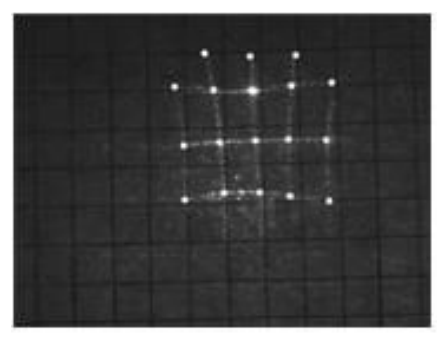

(a)

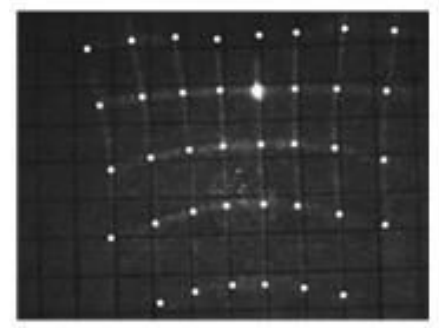

(e)

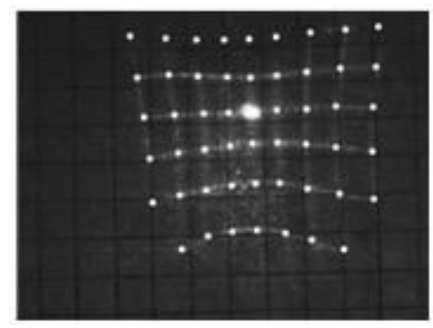

(i)

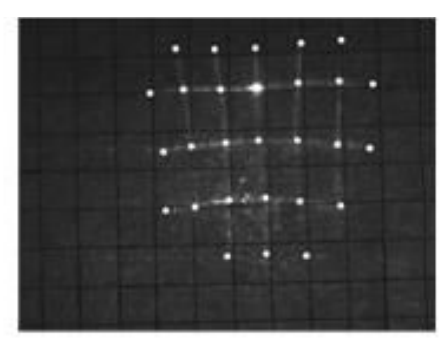

(b)

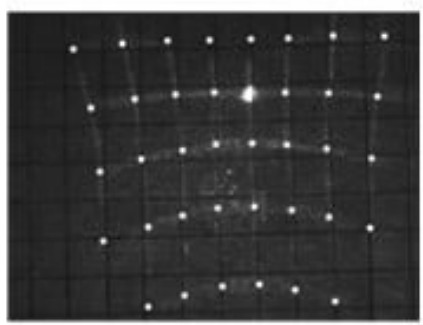

(f)

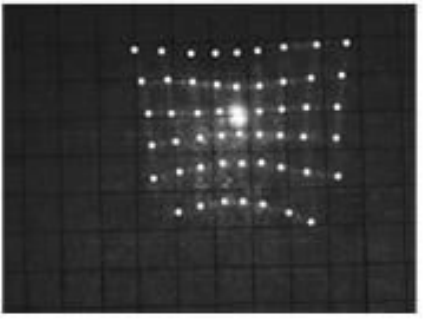

(j)

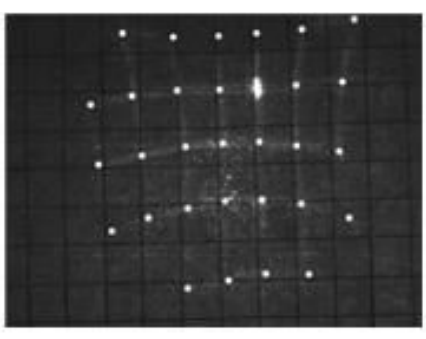

(c)

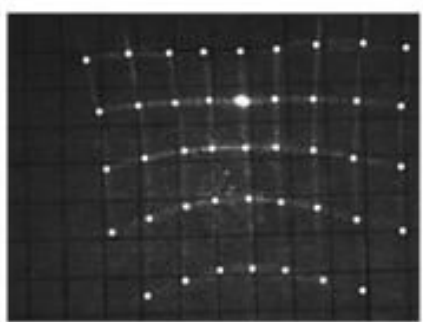

(g)

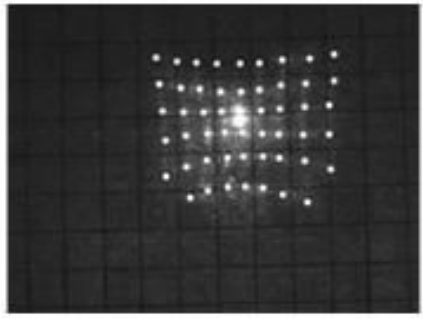

(k)

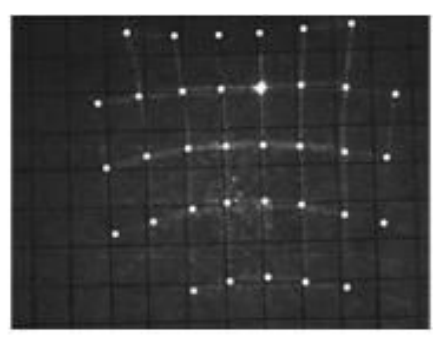

(d)

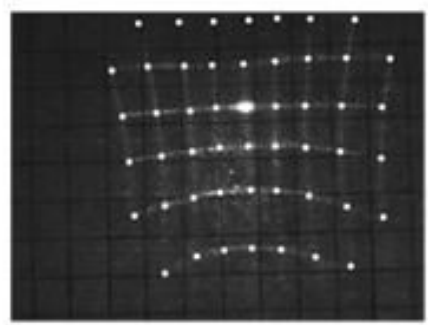

(h)

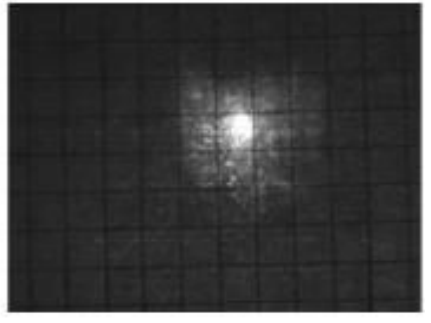

(1)

Figure 2

Laser dot matrix images at 70A in GTA welding

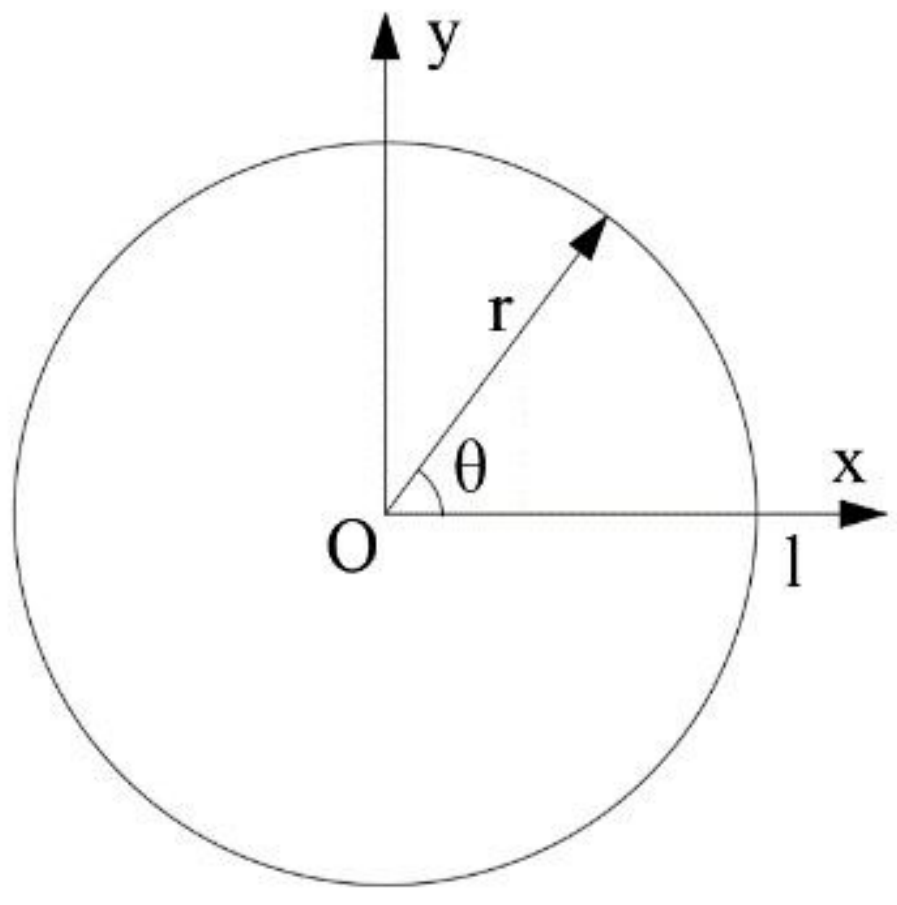


Figure 3

Transverse vibration of circular membrane

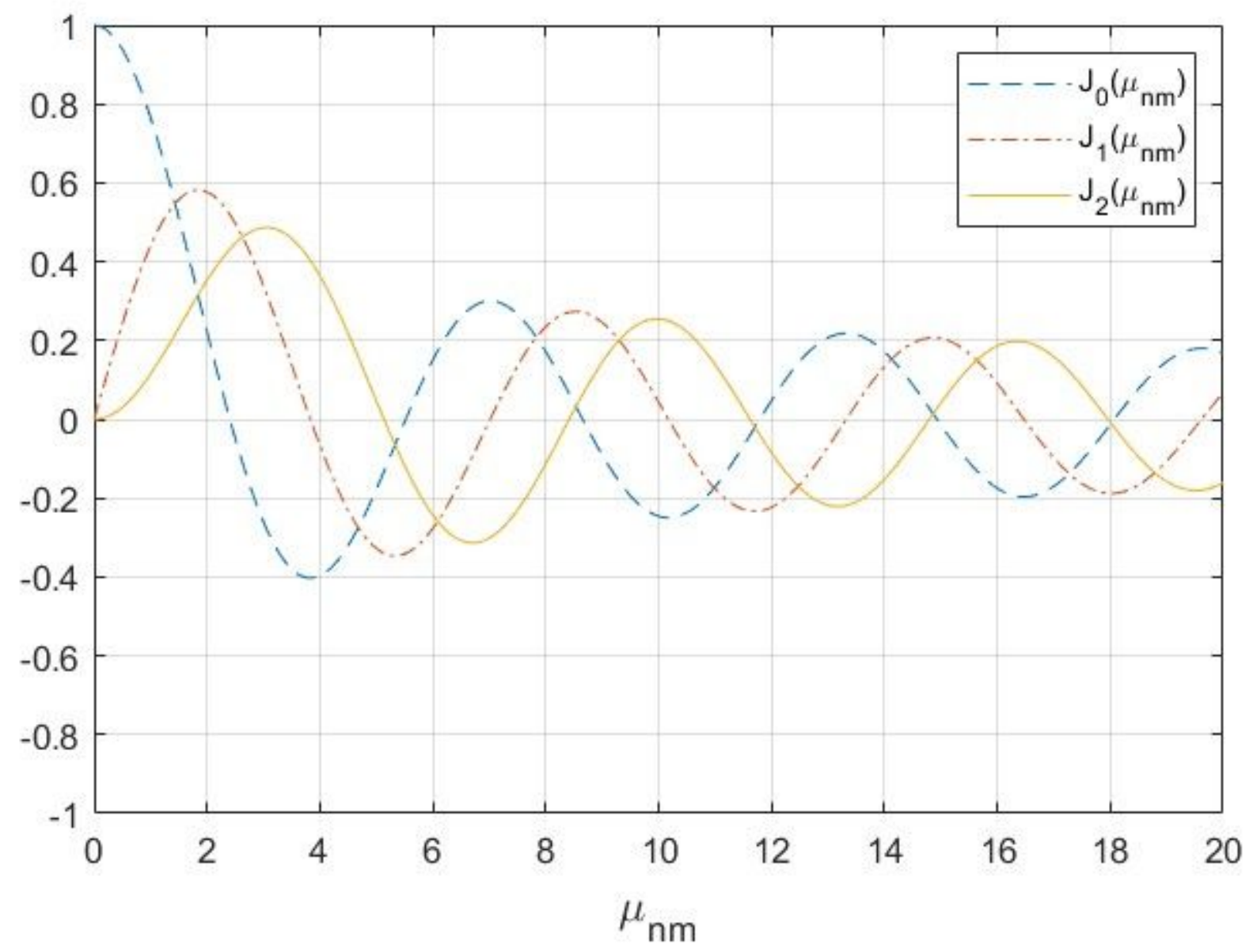

Figure 4

Plot of Bessel functions of the first kind 


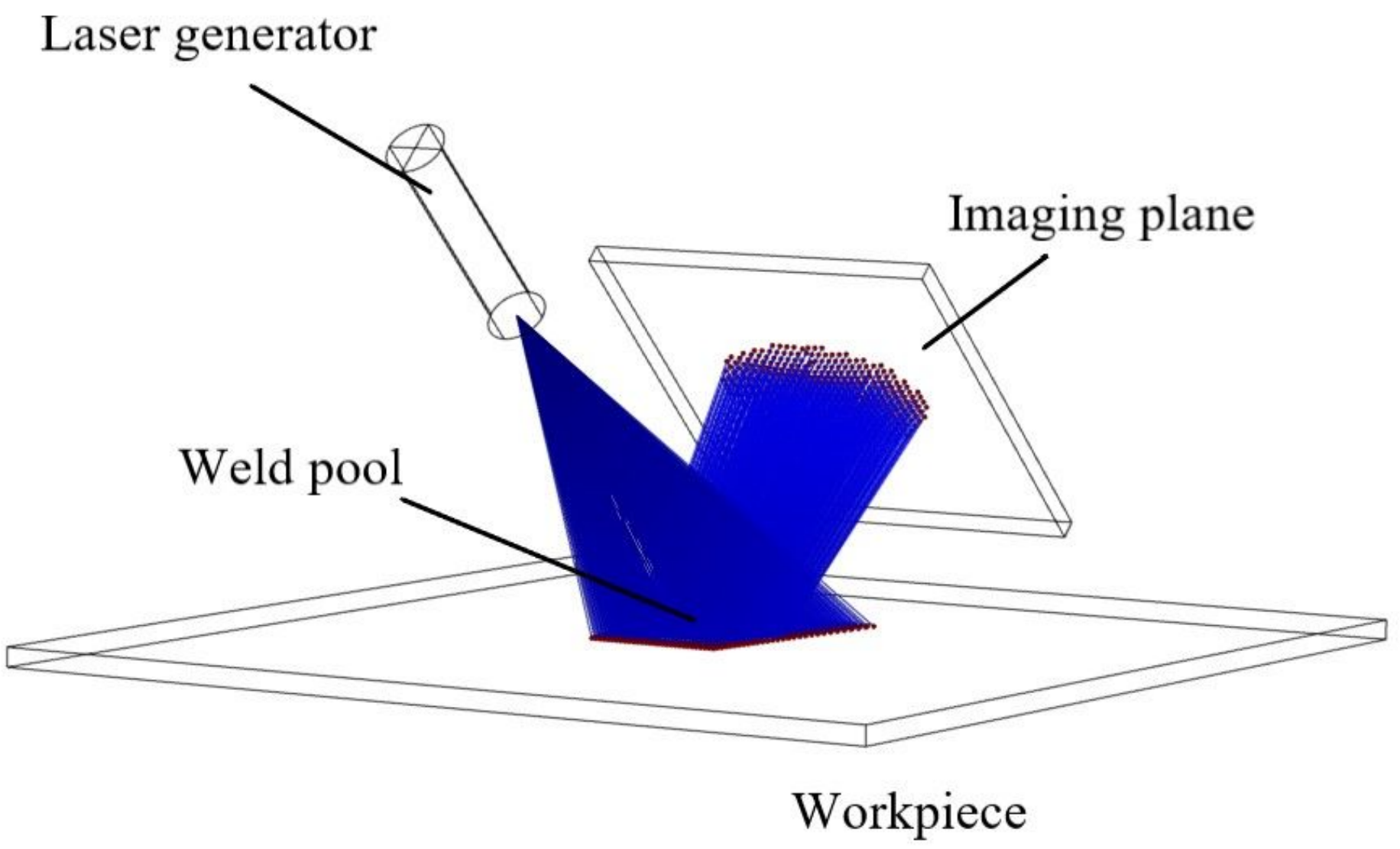

Figure 5

Integrated pool simulation platform 


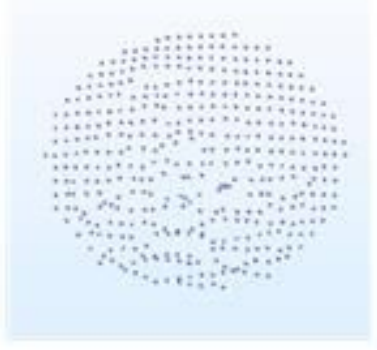

(a) $526 \mathrm{~ms}$

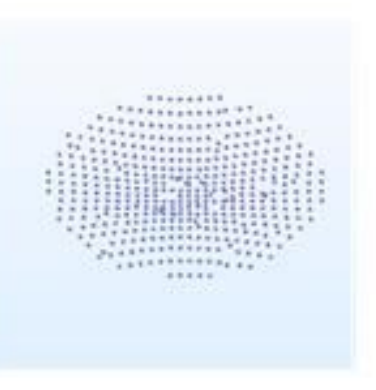

(e) $618 \mathrm{~ms}$

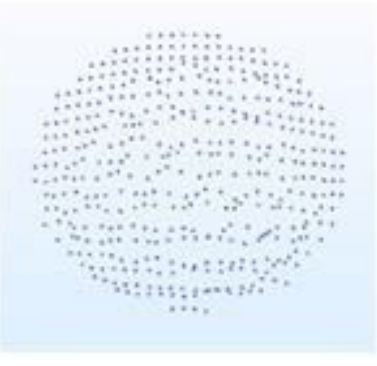

(i) $740 \mathrm{~ms}$

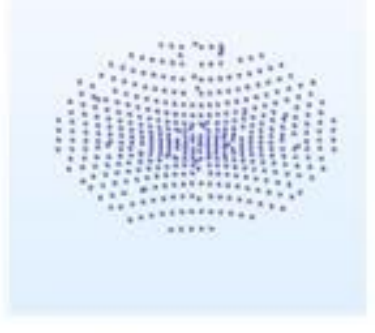

(b) $552 \mathrm{~ms}$

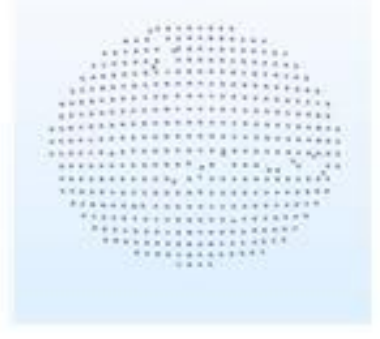

(f) $676 \mathrm{~ms}$

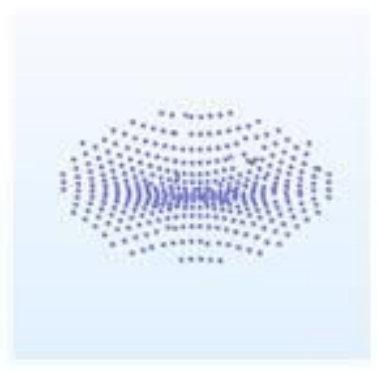

(j) $752 \mathrm{~ms}$

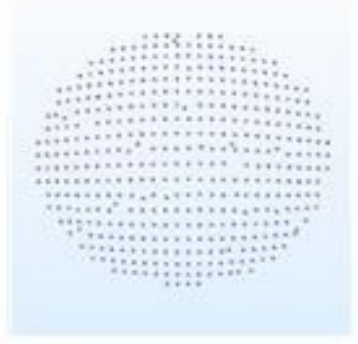

(c) $560 \mathrm{~ms}$

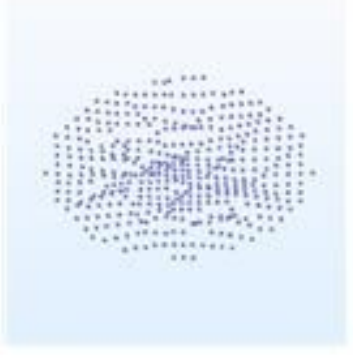

(g) $684 \mathrm{~ms}$

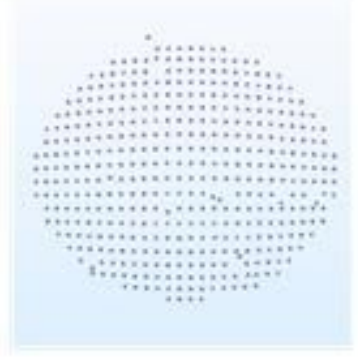

(k) $814 \mathrm{~ms}$ (d) $610 \mathrm{~ms}$

(h) $736 \mathrm{~ms}$
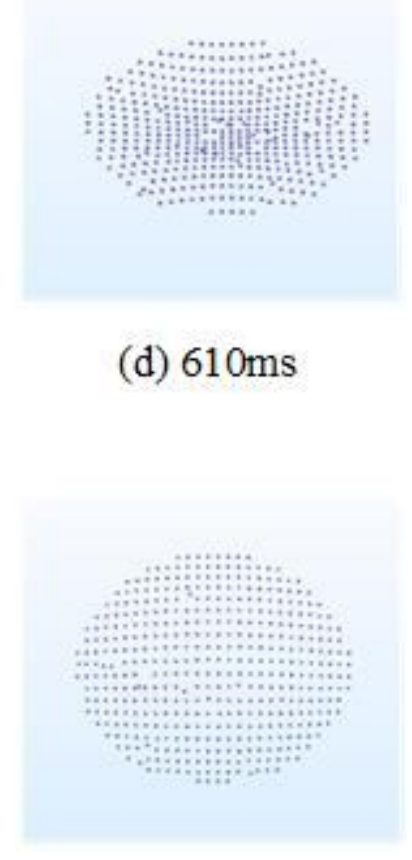

(d) $610 \mathrm{~ms}$

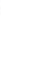

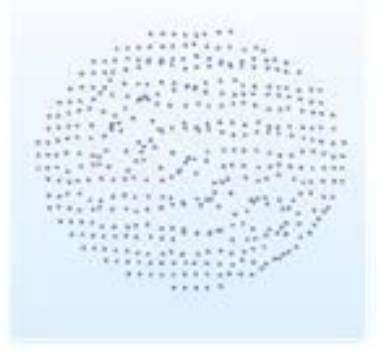

(1) $820 \mathrm{~ms}$

\section{Figure 6}

$(0,1)$ Mode laser dot matrix image 


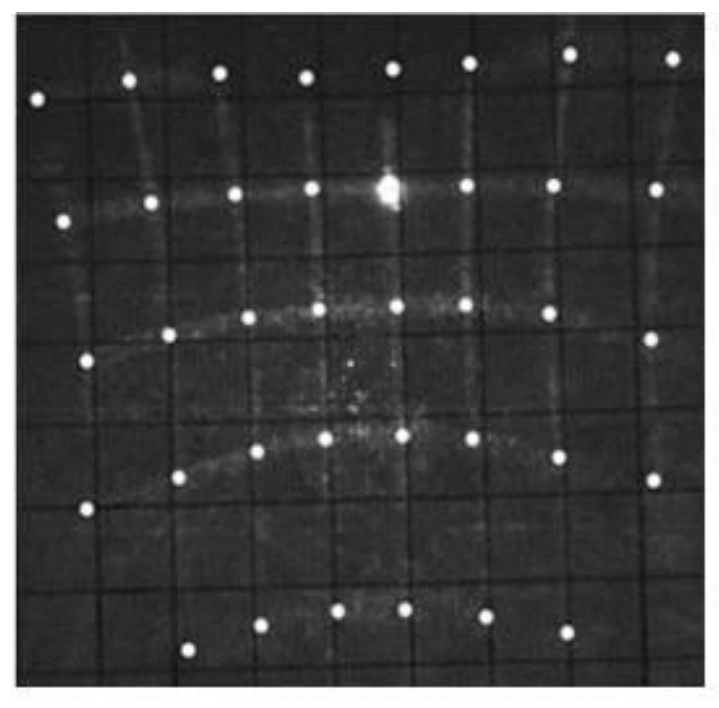

(a)

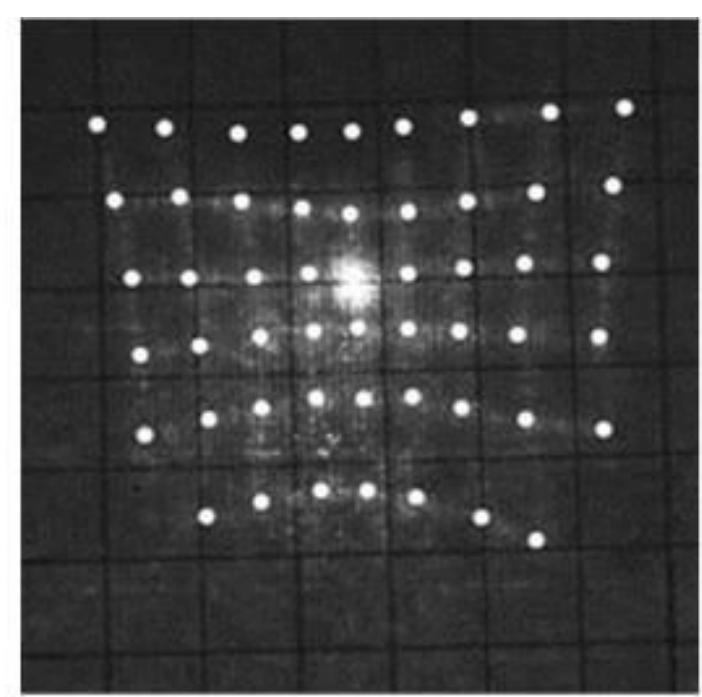

(b)

Figure 7

$(0,1)$ mode experiment results 


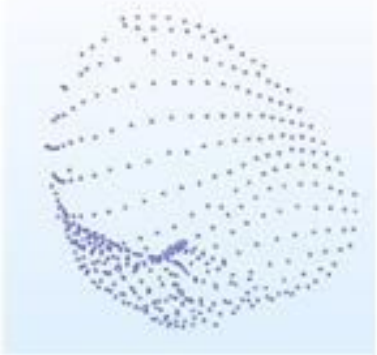

(a) $160 \mathrm{~ms}$

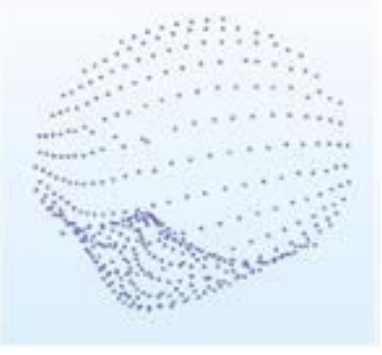

(e) $228 \mathrm{~ms}$

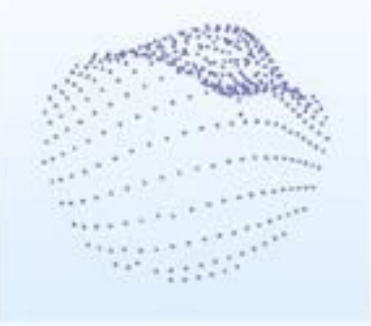

(i) $262 \mathrm{~ms}$

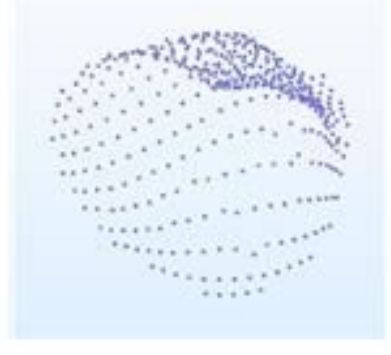

(b) $164 \mathrm{~ms}$

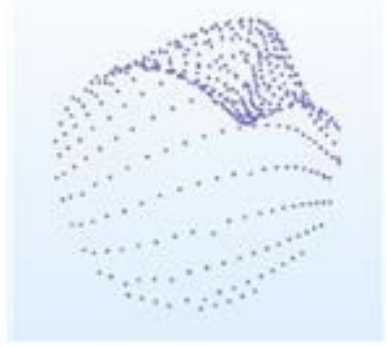

(f) $232 \mathrm{~ms}$

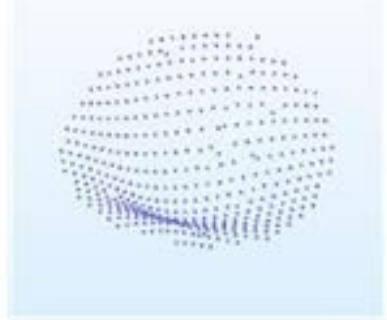

(j) $268 \mathrm{~ms}$

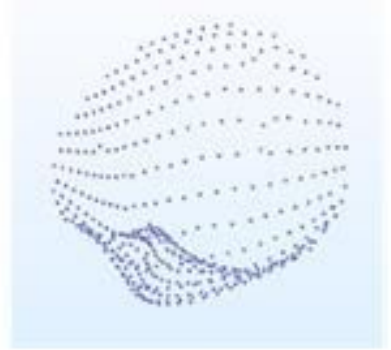

(c) $192 \mathrm{~ms}$

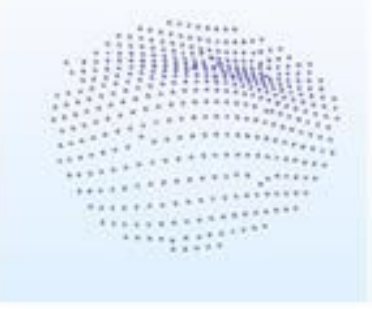

(g) $236 \mathrm{~ms}$

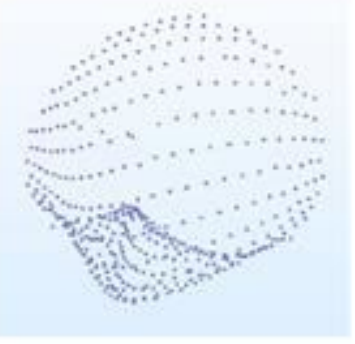

(k) $288 \mathrm{~ms}$

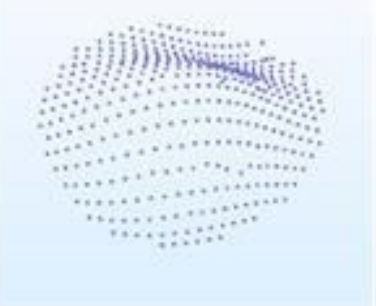

(d) $196 \mathrm{~ms}$

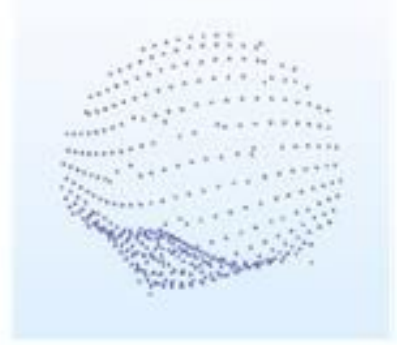

(h) $258 \mathrm{~ms}$

\section{Figure 8}

$(1,1)$ Mode laser dot matrix image 


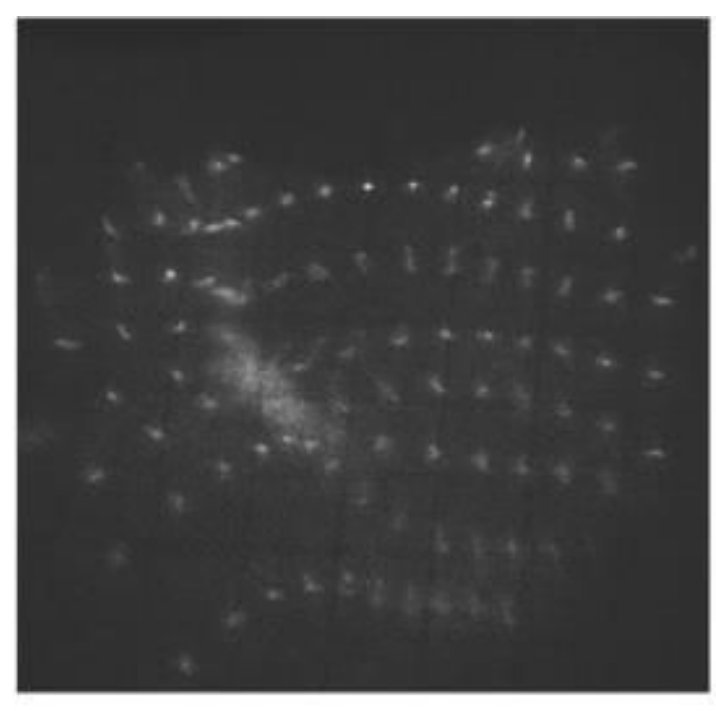

(a)

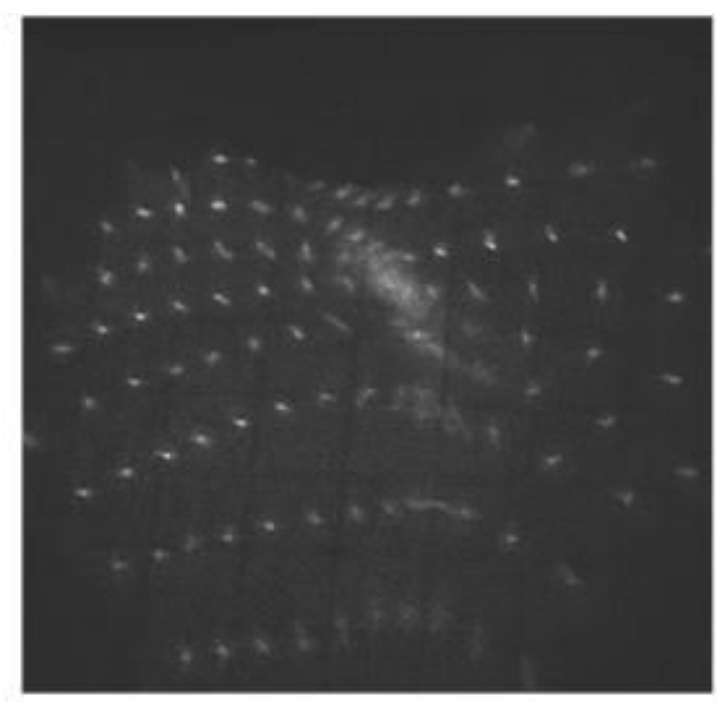

(b)

Figure 9

$(1,1)$ mode experiment results 


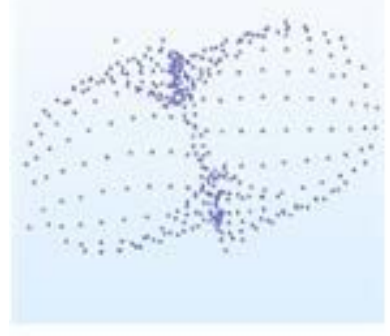

(a) $188 \mathrm{~ms}$

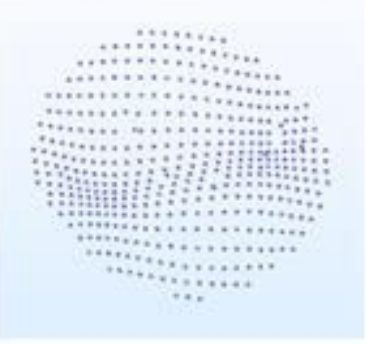

(e) $232 \mathrm{~ms}$

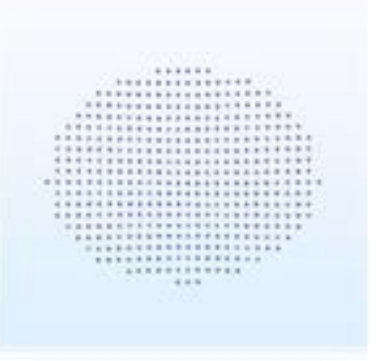

(i) $302 \mathrm{~ms}$

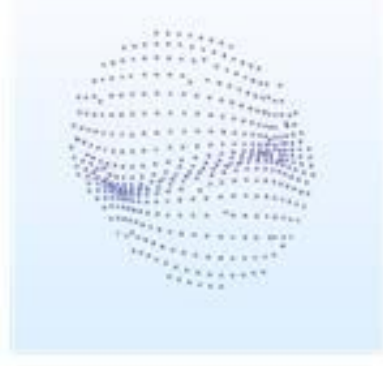

(b) $190 \mathrm{~ms}$

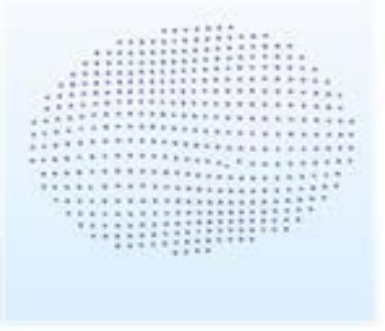

(f) $236 \mathrm{~ms}$

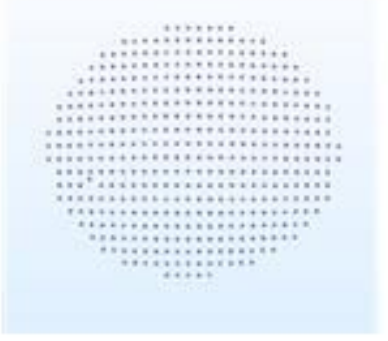

(j) $354 \mathrm{~ms}$

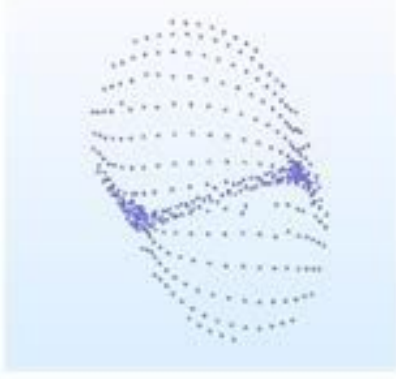

(c) $192 \mathrm{~ms}$

(d) $196 \mathrm{~ms}$

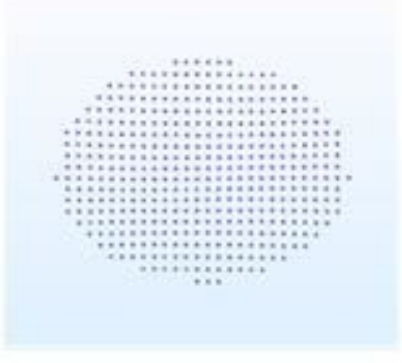

(g) $242 \mathrm{~ms}$

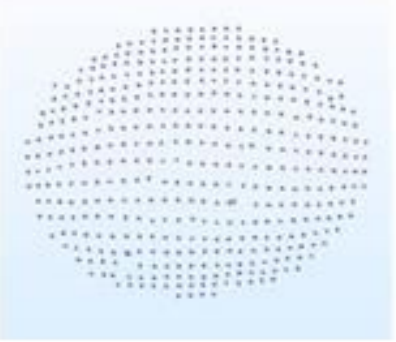

(k) $420 \mathrm{~ms}$
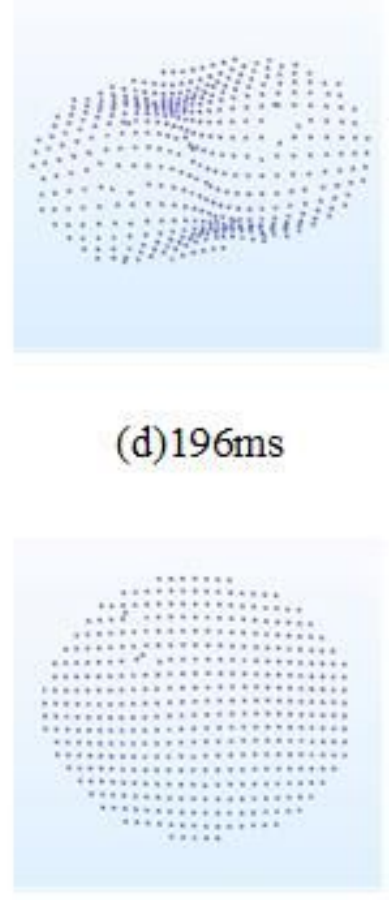

(h) $296 \mathrm{~ms}$

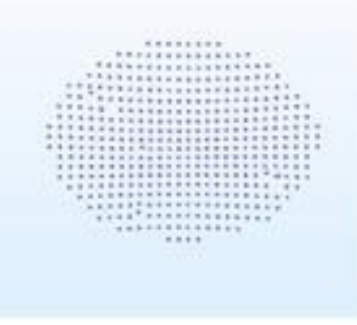

(1) $430 \mathrm{~ms}$

Figure 10

$(2,1)$ mode laser dot matrix image 


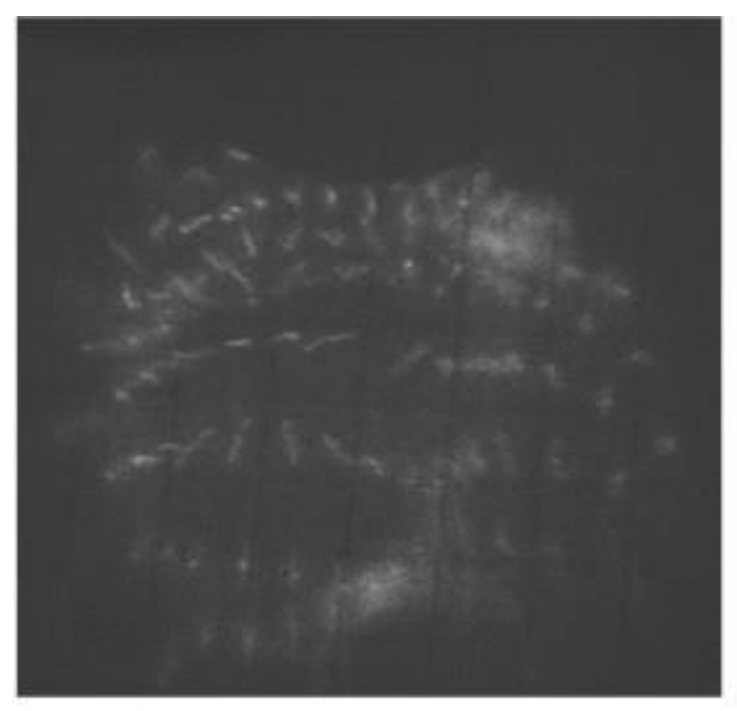

(a)

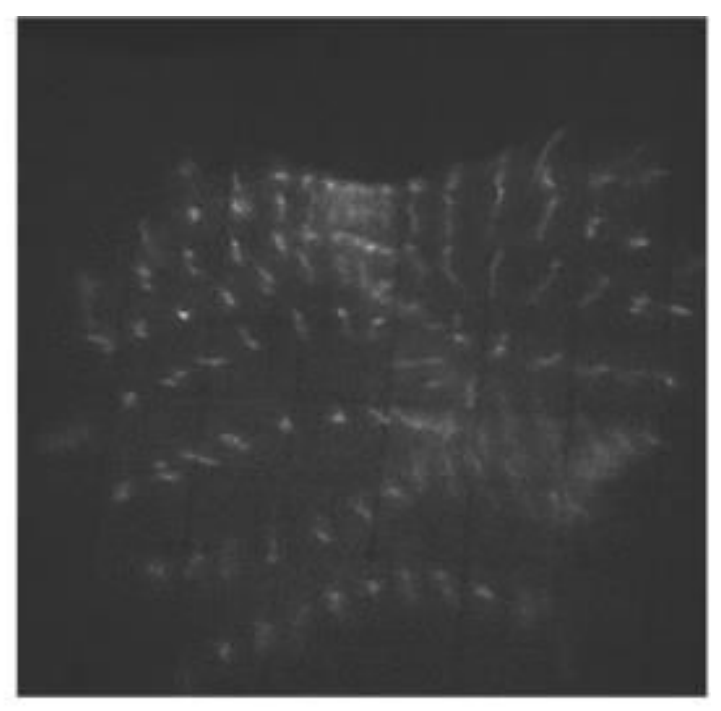

(b)

\section{Figure 11}

$(2,1)$ mode experiment results

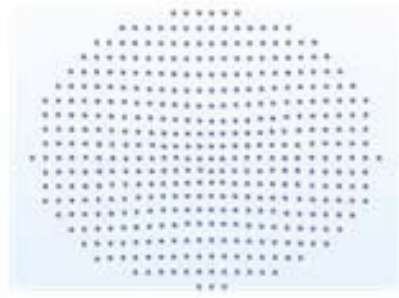

(a) $132 \mathrm{~ms}$

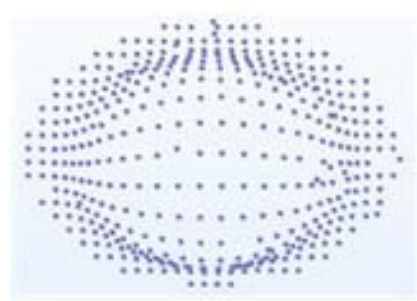

(e) $137 \mathrm{~ms}$

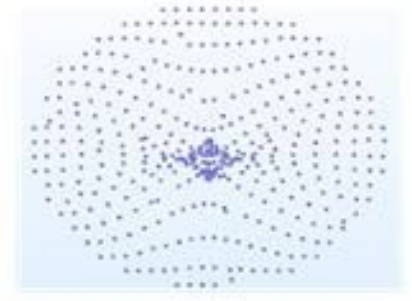

(b) $133 \mathrm{~ms}$

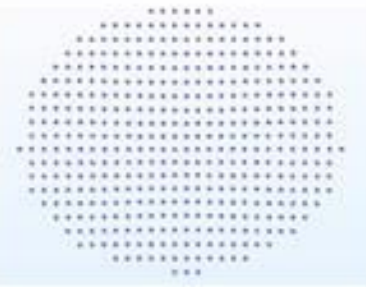

(f) $139 \mathrm{~ms}$

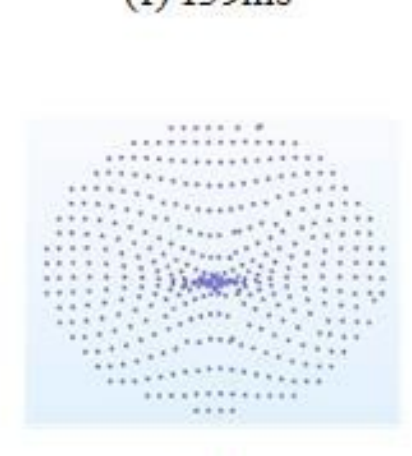

(j) $174 \mathrm{~ms}$

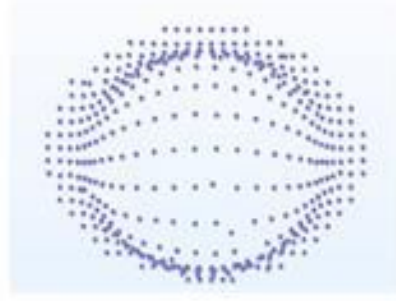

(c) $135 \mathrm{~ms}$

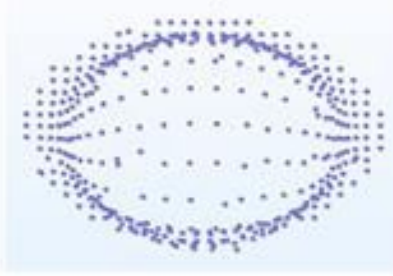

(d) $136 \mathrm{~ms}$ (i) $173 \mathrm{~ms}$

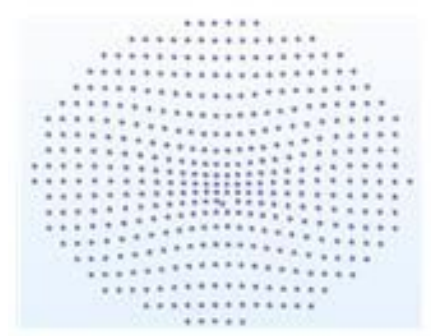

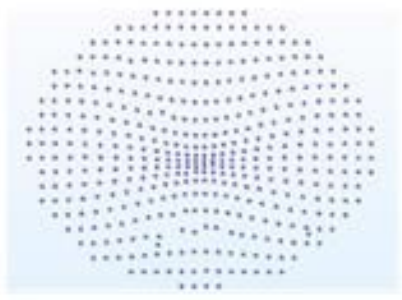

(g) $140 \mathrm{~ms}$

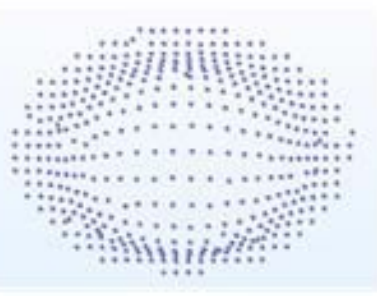

(h) $171 \mathrm{~ms}$

\section{Figure 12}




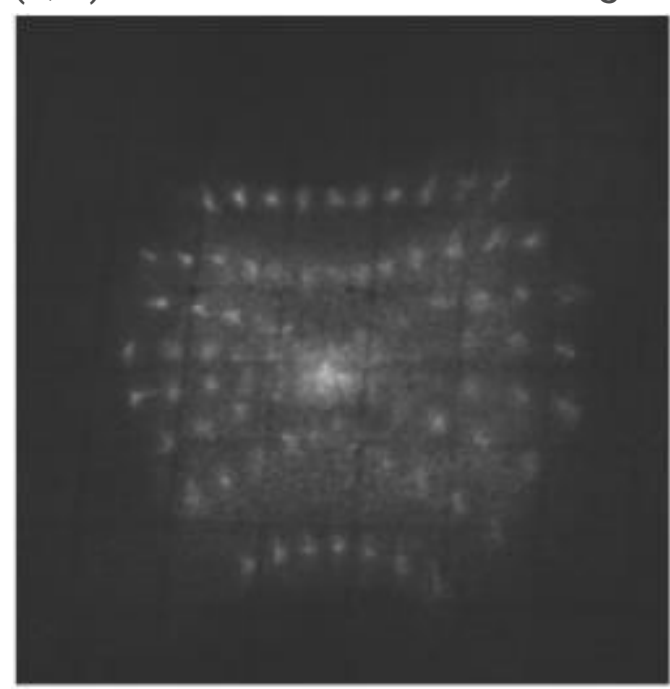

(a)

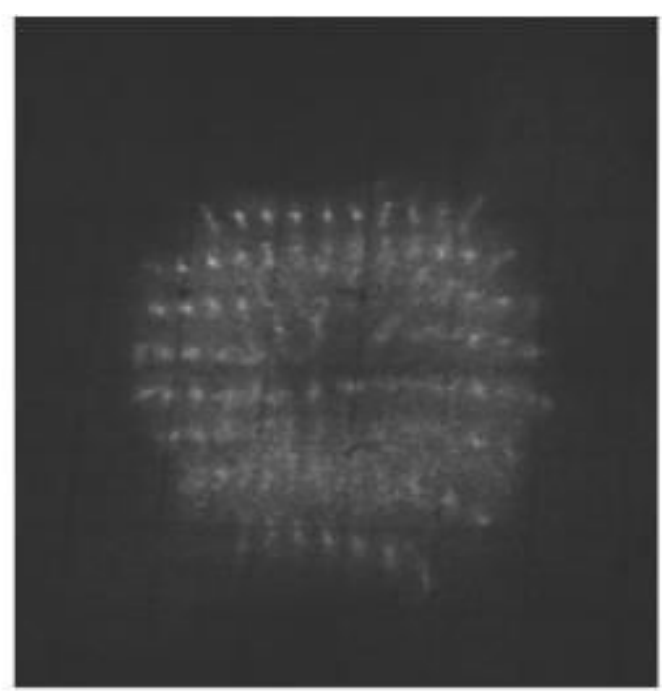

(b)

\section{Figure 13}

$(0,2)$ mode experiment results

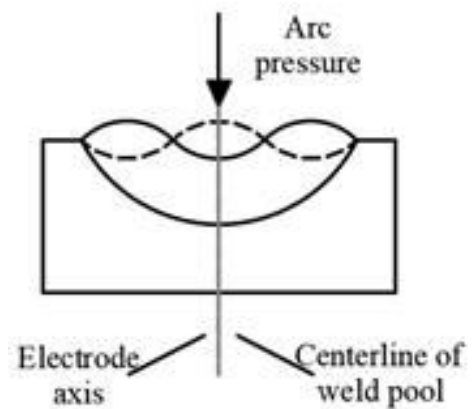

(a)

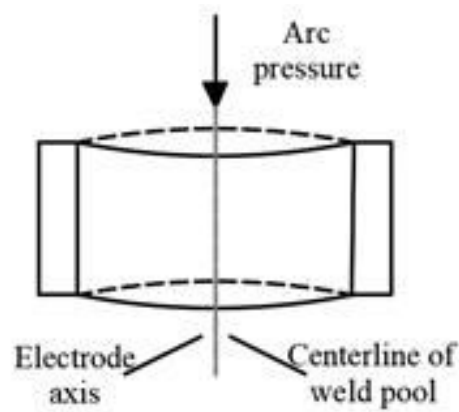

(b)

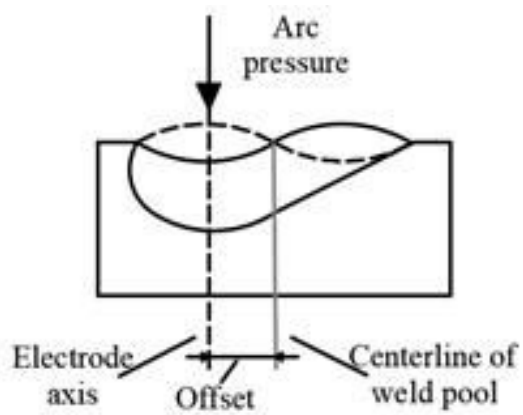

(c)

Figure 14

Different shapes of weld pool surface during welding process 